\title{
Schisandrin B suppresses osteosarcoma lung metastasis in vivo by inhibiting the activation of the Wnt/ק-catenin and PI3K/Akt signaling pathways
}

\author{
YUPING WANG $^{1}$, JIN CHEN ${ }^{2}$, YANRAN HUANG $^{1}$, SHENGDONG YANG $^{1}$, TAO TAN $^{1}$, NAN WANG $^{1}$, \\ JUN ZHANG ${ }^{1}$, CAIHONG YE $^{3}$, MENGQI WEI $^{3}$, JINYONG LUO $^{3}$ and XIAOJI LUO ${ }^{1}$ \\ Departments of ${ }^{1}$ Orthopedics and ${ }^{2}$ Dermatology, The First Affiliated Hospital of Chongqing Medical University; \\ ${ }^{3}$ Key Laboratory of Clinical Diagnosis of Education Ministry, College of Laboratory Medicine, \\ Chongqing Medical University, Chongqing 400016, P.R. China
}

Received July 3, 2021; Accepted December 16, 2021

DOI: $10.3892 /$ or.2022.8261

\begin{abstract}
Osteosarcoma (OS) is the most common malignant bone tumor worldwide and is associated with a poor prognosis, often being accompanied by lung metastasis at an early stage. At present, there are several side-effects associated with the OS clinical treatment of OS, with the treatment effects often being unsatisfactory. Thus, there is an urgent need for the development of safe and effective novel drugs for the treatment of OS. Schisandrin B (Sch B) has been previously demonstrated to exhibit antitumor properties. The present study was focused on the effects of Sch B on OS cells (143B, MG63, Saos2 and $\mathrm{U} 2 \mathrm{OS}$ ) in vitro and in vivo, and also on its possible antitumor mechanisms. In cell experiments, it was revealed that Sch B inhibited OS cell proliferation, migration and invasion, and increased OS cell apoptosis. As regards its biosafety, no notable effects of Sch B on the vitality of normal cells were observed. Mechanistically, it was demonstrated that Sch B blocked OS cell proliferation in the $G_{1}$ phase. Subsequently, by using established animal models, it was revealed that Sch B significantly inhibited OS growth and lung metastasis in vivo. In summary, the results of the present study revealed that Sch B inhibited OS cell proliferation, migration and invasion, and promoted apoptosis via the inhibition of the $\mathrm{Wnt} / \beta$-catenin and PI3K/Akt signaling pathways, without causing any noticeable
\end{abstract}

Correspondence to: Professor Xiaoji Luo, Department of Orthopedics, The First Affiliated Hospital of Chongqing Medical University, 1 Youyi Road, Yuzhong, Chongqing 400016, P.R. China E-mail: cy2982@163.com

Professor Jinyong Luo, Key Laboratory of Clinical Diagnosis of Education Ministry, College of Laboratory Medicine, Chongqing Medical University, 1 Yixueyuan Road, Yuzhong, Chongqing 400016, P.R. China

E-mail: luojinyong888@hotmail.com

Key words: Schisandrin B, osteosarcoma, Wnt/ $\beta$-catenin, PI3K, lung metastasis toxic effects on healthy cells at the therapeutic concentrations used. These findings suggest that Sch B has potential for use as a novel agent for the clinical treatment of OS.

\section{Introduction}

Osteosarcoma (OS) is the most common type of malignant bone tumor worldwide, particularly among young adults and children (1). Currently, surgical treatment and the use of chemotherapeutic drugs are the main treatment strategies for OS. However, the rate of early metastasis of OS is high, presenting considerable challenges to its successful treatment (2). OS pulmonary metastasis of is often an important factor contributing to a decreased patient survival rate. The emergence of neoadjuvant chemotherapy has improved the patient survival rate; however, drug resistance and chemotherapeutic side-effects have become a main issue of concern in patients treated using these neoadjuvant therapies $(3,4)$. Thus, the identification of safe and effective novel therapeutics is mandatory in order to address the aforementioned challenges.

Schisandrin B (Sch B), is an active dibenzooctadiene lignin that can be isolated from the fruit of Schisandra chinensis (a traditional Chinese herb) (5). In previously published studies, Sch B was demonstrated to play a crucial role in the treatment of cardiovascular and neurodegenerative diseases. Of particular interest was the anti-tumorigenic role attributed to Sch B, including the regulation of cell cycle arrest, apoptosis, reactive oxygen species production and autophagy (6). Treatment with Sch B has been reported to lead to the $G_{0} / G_{1}$ phase arrest of HCCC-9810 human cholangiocarcinoma cells, and to induce apoptosis via the upregulation of Bax, cleaved caspase-3, cleaved caspase-9 and cleaved poly(ADP-ribose) polymerase (PARP) levels (7). Furthermore, Sch B has been reported to inhibit prostate cancer cell proliferation and to promote DU145 and LNCaP cell apoptosis via S phase cell cycle arrest. Moreover, the apoptotic process induced by Sch B in LNCaP cells has been shown to be associated with the Sch B-induced oxidative stress increase, androgen receptor inhibition, and PI3K/AKT and STAT3/Janus kinase 2 phosphorylation (8). The anticancer potential of Sch B in triple-negative breast 
cancer (TNBC) has also been reported. Sch B has been reported to inhibit TNBC growth by inducing cell cycle arrest and triggering apoptotic death, with the mediation of the aforementioned inhibitory activities via the suppression of STAT3 phosphorylation and nuclear translocation (9). Additionally, Sch B has been reported to suppress malignant glioma cell (U251 and U87) migration and invasion via the PI3K/Akt/mTOR/MMP-9 signaling pathway (10). Sch B has also been demonstrated to exert anticancer effects on lung adenocarcinoma A549 cells by inhibiting A549 cell proliferation in a concentration-dependent manner and inducing cell cycle arrest at the $\mathrm{G}_{0} / \mathrm{G}_{1}$ phase (11).

The present study investigated the anticancer effects of Sch B on human OS cells (143B, MG63, Saos2 and U2OS) and the related mechanisms in vitro and in vivo. The 143B, MG63, Saos2 and U2OS cell lines were used herein, which are commonly used cell lines in OS research $(12,13)$.

\section{Materials and methods}

Cells and cell culture. The OS cell lines (143B, CRL-8303; MG63, CRL-1427; Saos2, HTB-851; and U2OS, HTB-96) and normal cells (HEB, CRL-8621; and HS5, CRL-11882) used were provided by Professor Tongchuan He (University of Chicago, USA), and were originally obtained from the American Type Culture Collection. The cells were cultured in DMEM (HyClone; Cytiva), supplemented with 10\% FBS (Shanghai ExCell Biology, Inc.) and 1\% penicillin-streptomycin (100 IU/ml; Hyclone; Cytiva). The OS cells were cultured in 90- or 60-mm cell culture dishes, in a humidified incubator at $37^{\circ} \mathrm{C}$ with $5 \% \mathrm{CO}_{2}$. The cells to be passaged were washed with PBS (Gibco; Thermo Fisher Scientific, Inc.) and treated with $0.25 \%$ trypsin-EDTA (Thermo Fisher Scientific, Inc.) for subsequent subculturing.

Drug preparations. Sch B (purity $\geq 98 \%$ ) was purchased from Chengdu Herburify Co., Ltd. (http://www.herbpurify. com/). A total of $20 \mathrm{mg}$ Sch B was dissolved in $1.5 \mathrm{ml}$ DMSO (SigmaAldrich; Merck KGaA). Sch B was stored at $-80^{\circ} \mathrm{C}$ and used for subsequent use in in vitro cell experiments by diluting immediately prior to application. For the in vivo experiments, $200 \mathrm{mg}$ Sch B were dissolved in $40 \mathrm{ml}$ carboxymethyl cellulose (SigmaAldrich; Merck KGaA) and stored at $-80^{\circ} \mathrm{C}$ following ultrasonication overnight.

Crystal violet assay. The OS cells (143B, MG63, Saos2 and U2OS) were seeded into 24 well-plates at a concentration of $2.5 \times 10^{4}$ cells/well. The OS cells were first treated with various concentrations of Sch B $(0,20,40,60,80$ or $100 \mu \mathrm{M})$, in order to determine the effective concentration range (data not shown). The cells (at 50\% confluency) were then treated with various concentrations of Sch B $(0,20,40,60$ or $80 \mu \mathrm{M})$ or DMSO (vehicle control). Following treatment for 24,48 and $72 \mathrm{~h}$, the cells were washed with $4^{\circ} \mathrm{C}$ PBS three times and fixed with $4 \%$ paraformaldehyde for $20 \mathrm{~min}$ at $25^{\circ} \mathrm{C}$. After removing the $4 \%$ paraformaldehyde, crystal violet dye (Beyotime Institute of Biotechnology) was added to the 24-well plate for $3 \mathrm{~min}$ in the dark at $25^{\circ} \mathrm{C}$. Subsequently, the excess crystal violet dye was washed with double distilled water. The 24 well-plates were dried and imaged using an Epson Perfection
V200 Photo (Epson). For quantification analysis, $200 \mu 120 \%$ acetic acid solution were added to each well to dissolve the crystal violet for $10 \mathrm{~min}$ with constant shaking in the dark at $25^{\circ} \mathrm{C}$. The absorbance was measured at $595 \mathrm{~nm}$ in a multifunctional enzyme labeled detector (BioTek_Synergy4; Gene Company, Ltd.).

MTT assay. MTT powder was purchased from Sigma-Aldrich; Merck KGaA. The OS cells were seeded in 96-well plates $\left(3 \times 10^{3}\right.$ cells/well). OS cells were first treated with various concentrations of $\operatorname{Sch} \mathrm{B}(0,20,40,60,80$ or $100 \mu \mathrm{M})$ to determine the effective concentration range (data not shown). The OS cells (at $50 \%$ confluency) were treated with various concentrations of Sch B $(0,20,40,60$ or $80 \mu \mathrm{M})$ or DMSO. Normal cells were treated in the same manner, but with a larger range of concentrations $(0-200 \mu \mathrm{M})$. Following 24,48 and $72 \mathrm{~h}$ treatment, $10 \mu \mathrm{l}$ of $5 \mathrm{mg} / \mathrm{ml}$ MTT solution (Sigma-Aldrich; Merck KGaA) were added to each well of the 96-well plate and incubated for $4 \mathrm{~h}$ at $37^{\circ} \mathrm{C}$. The solution was then removed using a 1-ml syringe and $100 \mu \mathrm{l}$ DMSO were added to each well. Following a 15 -min agitation at $25^{\circ} \mathrm{C}$, the absorbance in the wells was detected at $492 \mathrm{~nm}$ using a multifunctional enzyme labeled detector (BioTek_Synergy4 Gene Company, Ltd.). The following formula was used to determine the $\mathrm{IC}_{50}$ values: $\operatorname{lgIC}=\mathrm{Xm}-\mathrm{I}[\mathrm{P}-(3-\mathrm{Pm}-\mathrm{Pn}) / 4]$, where $\mathrm{Xm}$ is the maximum drug concentration, $\mathrm{I}$ is the maximum drug concentration/adjacent drug concentration, $\mathrm{P}$ is the sum of positive reaction rates, $\mathrm{Pm}$ is the maximum positive reaction rate and $\mathrm{Pn}$ is the minimum positive reaction rate.

Colony formation assay. The 143B cells were seeded into 6 -well plates ( 200 cells/well). Considering the high cell density of the colony formation assay and the purpose of the experiment, the OS cells were first treated with lower concentrations of Sch B $(0,3,5,7,9,11,13,15,17$ or $19 \mu \mathrm{M})$ to determine the effective concentration range (data not shown). The cells were then treated with various concentrations of Sch B $(0,3,5,7$ or $9 \mu \mathrm{M})$ or DMSO when clusters of 2-3 cells could be observed under a light microscope (ECLIPSE Ti, Nikon Corporation, White Light, x100 magnification). Following 2 weeks of culture, all cells were stained with crystal violet (Beyotime Institute of Biotechnology) as aforementioned, and dried and imaged using an Epson Perfection V200 Photo (Epson). The number of colonies were counted, and a cluster of cells was considered a colony if it consisted of $>50$ cells.

Wound healing assay. The 143B and MG63 were seeded into 6 -well plates to evaluate the changes in the cell migratory capability in Sch B-treated cells. When the cells had grown to $90 \%$ confluency, a sterile pipette tip was used to create a wound in the cell monolayer. The floating cells were washed using PBS. Serum-starved medium (HyClone; Cytiva) was used during the wound healing assay. Considering the high cell density required for the wound healing assay, the OS cells were first treated with large concentrations of Sch B $(0,30$, $50,70,90,110,130,150,170$ or $190 \mu \mathrm{M})$ to determine the effective concentration range before formal experiments (data not shown). All cells were treated with various concentrations of Sch B $(0,30,50,70$ or $90 \mu \mathrm{M})$ or DMSO, and incubated for $24 \mathrm{~h}$ at $37^{\circ} \mathrm{C}$. The wound width was recorded using an inverted 
microscope (ECLIPSE Ti; Nikon Corporation, White Light, x100 magnification) after 0,12 and $24 \mathrm{~h}$. The following formula was used to determine the healing ability of the treated cells as a percentage: [(Start scratch width-end scratch width)/(start scratch width)] x100.

Transwell assays. Transwell chamber inserts $(8-\mu \mathrm{m}$ pores; MilliporeSigma) were placed in 24-well plates. For the migration assay, $2.5 \times 10^{4}$ cells were resuspended in $400 \mu \mathrm{l} \mathrm{FBS}$-free medium (HyClone; Cytiva) and added to the upper chamber. The OS cells were first treated with various concentrations of Sch B $(0,20,40,60,80$ or $100 \mu \mathrm{M})$ to determine the effective concentration range (data not shown). Subsequently, media (HyClone; Cytiva) supplemented with 10\% FBS as a chemotactic agent with various Sch B concentrations $(0,20,40,60$ or $80 \mu \mathrm{M})$ were placed in the lower compartment. For the invasion assay, $30 \mu \mathrm{l}$ Matrigel (BD Biosciences) diluted with $270 \mu 1$ DMEM was placed in each filter (50 $\mu 1$ per) to create the matrix adhesive film. Subsequently, all remaining experimental steps were performed in the same manner as those described above for the migration assay. Following $24 \mathrm{~h}$ of incubation at $37^{\circ} \mathrm{C}$, the cells that had not invaded or migrated were removed using a cotton swab. Filters were stained with crystal violet as aforementioned and subsequently wiped with a cotton swab for the removal of the excess dye. Finally, the number of cells which had migrated or invaded were imaged (ECLIPSE Ti; Nikon Corporation) and counted in a random field of view (magnification, White Light, x100 magnification).

Hoechst 33258 staining assay. The OS cells were first treated with various concentrations of Sch B $(0,20,40$, $60,80$ or $100 \mu \mathrm{M})$ to determine the effective concentration range (data not shown). The OS cells were seeded into 6 -well plates and treated with various concentrations of Sch B $(0,20,40,60$ or $80 \mu \mathrm{M})$ or DMSO when the cell density reached $50 \%$. Following $24 \mathrm{~h}$ of treatment, the cells were fixed with $4 \%$ paraformaldehyde for $20 \mathrm{~min}$, washed with cold PBS, and stained with $10 \mathrm{ng} / \mathrm{ml}$ Hoechst 33258 (Beijing Solarbio Science \& Technology Co., Ltd.) for $10 \mathrm{~min}$ in the dark at $25^{\circ} \mathrm{C}$. Finally, the apoptotic cells were imaged (ECLIPSE Ti; Nikon Corporation) and counted in a random field of view (magnification, fluorescence, $x 100$ magnification).

Flow cytometric analysis. The OS cells were cultured in $60-\mathrm{mm}$ dishes. The cells were treated with various concentrations of Sch B $(0,20,40,60$ or $80 \mu \mathrm{M})$ or DMSO when the cell density reached $50 \%$, for $24 \mathrm{~h}$. The cells in each dish were digested with trypsin and placed in $500 \mu 1$ PBS for $1 \mathrm{~min}$ at $25^{\circ} \mathrm{C}$, stained with annexin V-FITC/PI (Beyotime Institute of Biotechnology) and analyzed using a flow cytometer (BD Biosciences) to detect the apoptotic rate at each stage and analyzed using FlowJo software (version 10.4.0; BD Biosciences). For determining the cell cycle distribution, the cells were digested with trypsin and placed in $500 \mu 170 \%$ ethanol solution overnight at $4^{\circ} \mathrm{C}$, with the subsequent application of all previously described experimental procedures. A CytoFLEX flow cytometer (Beckman Coulter, Inc.) was used to detect the cell cycle distribution.
Network pharmacology analysis. Firstly, the 3D chemical structure of Sch B was obtained using PubChem (https://pubchem. ncbi.nlm.nih.gov/), and the drug target of Sch B was then obtained using the PharmMapper (http://www.lilab-ecust. cn/pharmmapper/), CTD (http://ctdbase.org/) and STITCH databases (http://stitch.embl.de/). The OS target genes were then collected from the GeneCards database (https://genecards. weizmann.ac.il/v3/), and the drug disease intersection genes were finally obtained. The protein interaction network was constructed using the STRING database (https://string-db. org/) (14), and the Sch B OS target protein regulatory network was visualized using Cytoscape (15). The node degree value was calculated and the key genes were screened. The target gene Gene Ontology (GO) functional annotations and Kyoto Encyclopedia of Genes and Genomes (KEGG) signaling pathway enrichment analysis were performed using $\mathrm{R}$ and $\mathrm{R}$ studio (version 3.4.0) (16-20).

Western blot analysis. The 143B cells cultured in 90-mm dishes were treated with Sch B $(0,40,60$ or $80 \mu \mathrm{M})$ or DMSO for $24 \mathrm{~h}$. For protein extraction, the cells were washed with cold PBS three times and $1 \mathrm{ml}$ pre-cooled lysate was added (Wuhan Boster Biological Technology, Ltd.) to lyse the cells. After boiling with $1 \mathrm{X}$ SDS loading buffer for 5 min, the protein concentration was measured using BCA protein assays (Beyotime Institute of Biotechnology). For electrophoresis, $35 \mu \mathrm{g}$ protein samples were loaded on $10 \%$ SDS gels and resolved using SDS-PAGE. When the target protein was $\sim 1 \mathrm{~cm}$ away from the lower edge of the gel, electrophoresis was terminated, and the resolved proteins were transferred to PVDF membranes (MilliporeSigma). The membranes were blocked in 5\% BSA (Beijing Solarbio Science \& Technology Co., Ltd.) for $30 \mathrm{~min}$ at $37^{\circ} \mathrm{C}$, and the membranes were incubated with specific primary antibodies $[\beta$-actin (cat. no. 3700), proliferating cell nuclear antigen (PCNA; cat. no. 13110) $\beta$-catenin (cat. no. 8480), c-Myc (cat. no. 18583), cyclin D1 (cat. no. 55506), GSK-3 $\beta$ (cat. no. 12456), Bcl-2 (cat. no. 15071), Bad (cat. no. 9268), Bax (cat. no. 14796), caspase-3 (cat. no. 9662), cleaved caspase-3 (cat. no. 9661), PARP (cat. no. 9532), cleaved-PARP (cat.no. 5625), MMP-2 (cat. no. 40994), MMP-7 (cat. no. 3801), MMP-9 (cat. no. 13667), vimentin (cat. no. 5741), E-cadherin (cat. no. 14472), N-cadherin (cat. no. 13116), cyclin E (cat.no.4129), Akt (cat. no. 4685),p-Akt(Ser473; cat.no.4060), phosphorylated (p-)Akt (Thr308; cat. no. 4070); dilution 1:1,000 for all the aforementioned antibodies; all from Cell Signaling Technology, Inc.] at $4^{\circ} \mathrm{C}$ overnight in 5\% BSA (Cell Signaling Technology, Inc.). The secondary antibodies used (anti-mouse IgG cat. no. 7076, anti-rabbit IgG, cat. no. 7074; dilution 1:1,000; both from Cell Signaling Technology, Inc.) was selected based on the source of the primary antibody, and the PVDF membranes were incubated with the secondary antibodies at room temperature for $1 \mathrm{~h}$. The membranes were then washed with TBS-Tween-20 three times, 10 min each time, and an enhanced chemiluminescent kit (MilliporeSigma) was used to visualize the proteins with a ChemiDoc MP Imaging system and Image Lab Software (version 5.2.1; Bio-Rad Laboratories, Inc.). All bands presented together were probed on the same membrane in order for the proteins to share the same loading control. 
Rescue assay. The 143B cells were treated with the Wnt signaling pathway agonist (BML284; cat. no. S8178) and Akt phosphorylation activator (SC79; cat. no. S7863) purchased from Selleck Chemicals in combination with Sch B. Subsequently, the effects of BML284 and SC79 were observed using crystal violet, wound healing and Transwell assays, as well as flow cytometric analysis.

Establishment of an orthotopic OS tumor animal model. In the present study, all experimental procedures involving animals were reviewed and approved by the Ethics Committee of the First Affiliated Hospital of Chongqing Medical University (approval no. 2020-503), and experiments were performed in accordance with the guidelines of the Declaration of Helsinki (21). A total of $15 \mathrm{BALB} / \mathrm{c}$ nude mice (female, 28 days old, weighing 16.5-18.5 g) were purchased from Beijing Huafukang Biotechnology Co., Ltd. The mice were reared under specific pathogen-free conditions and allowed to acclimatize for 1 week without any treatment. The environment was maintained at a constant temperature of $24^{\circ} \mathrm{C}$ and at $55 \%$ humidity, with a $12 \mathrm{~h}$ light/dark cycle. All the mice had free access to food and water. $143 \mathrm{~B}$ cells $\left(2.5 \times 10^{6}\right)$ in $60 \mu \mathrm{l}$ PBS were injected into the tibial plateau of the mice through the proximal tibia. At 3 days after the injection of the tumor cells, the mouse vital signs were observed. Afterwards, 15 mice were randomly divided into five groups, with 3 mice per group. One group was selected as the control group, and the remaining four groups were administered various doses of Sch B $(25,50$ or $75 \mathrm{mg} / \mathrm{kg})$ or $0.5 \%$ sodium carboxymethyl cellulose by intra-gastric administration every other day. The mouse weight and tumor size (length and width) were recorded prior to each administration. Mouse survival was judged by observing the respiratory movements and heartbeat of the mice. Mouse death was verified when no breathing and heartbeat were observed for $>3 \mathrm{~min}$. The animal survival rate was evaluated for up to 40 days. The experimental animals were euthanized when obvious cachexia, infection and excessive tumor volume were observed. However, there were no animals that required euthanasia during the experiment due to the reasons stated above. In addition, no animals died during the experiment. Following 15 treatments, all mice were euthanized by $\mathrm{CO}_{2}$ with a flow rate of $30 \%$ volume displacement $/ \mathrm{min}$. Tumor tissue and lungs were removed and fixed in $4 \%$ paraformaldehyde. The maximum observed length and width of the tumors were 18 and $16 \mathrm{~mm}$, respectively, and the tumor volume did not exceed $2,500 \mathrm{~mm}^{3}$.

$H \& E$ staining and immunohistochemistry. Tumor and lung tissues were fixed with $4 \%$ paraformaldehyde at $4^{\circ} \mathrm{C}$ for $72 \mathrm{~h}$, and embedded in paraffin. Paraffinembedded tumor samples were cut into $5-\mu \mathrm{m}$-thick sections. The wax on the section surface was removed by heating and soaking in various concentrations of alcohol (100, 90, 80 and 70\%). The OS tumor sections and lung tissues were then stained with $\mathrm{H} \& \mathrm{E}$ (Beyotime Institute of Biotechnology) at $37^{\circ} \mathrm{C}$ for $1 \mathrm{~min}$, to visualize tumor tissue lung metastasis. The same embedded sections and dewaxing methods used for the tumor and lung tissues in H\&E staining were used also to perform immunohistochemistry. For immunohistochemistry, the OS tumor tissue sections were incubated with specific histochemical antibodies [PCNA (cat. no. 13110),
Bcl-2 (cat. no. 15071), Vimentin (cat. no. 5741), p-Akt (Ser473; cat. no. 4060) and $\beta$-catenin (cat. no. 8480); dilution for all antibodies, 1:100; Cell Signaling Technology, Inc.] at $4^{\circ} \mathrm{C}$ overnight, and probed with HRPconjugated secondary antibody (anti-rabbit IgG cat. no. ab6721; dilution 1:350; Abcam) at $37^{\circ} \mathrm{C}$ for $30 \mathrm{~min}$, and then imaged under a light microscope (ECLIPSE Ti, Nikon Corporation, magnification, x200 and $\mathrm{x}$ 400).

Statistical analysis. All experiments were repeated three times to eliminate errors. All data are presented as the mean \pm standard deviation and were analyzed using GraphPad Prism version 5.0 (GraphPad Software, Inc.). A one-way ANOVA followed by a Tukey's post hoc test was used for conducting comparisons between multiple groups. $\mathrm{P}<0.05$ was considered to indicate a statistically significant difference.

\section{Results}

Sch B inhibits the proliferation of OS cells. Firstly, the inhibitory effects of Sch B on OS cell (143B, MG63, Saos2 and U2OS) proliferation were observed using crystal violet staining, and quantitative analysis demonstrated that the inhibitory effects of Sch B on OS cell proliferation were concentration-dependent (Fig. 1A and B). An MTT assay was used to further verify the effects of Sch B on OS cell viability and evaluate its toxic effects on normal cells from the perspective of safety. Following $48 \mathrm{~h}$ of treatment, the $\mathrm{IC}_{50}$ values in the $\mathrm{OS}$ cells were $70.32 \mu \mathrm{M}$ (143B cells), 58.68 $\mu \mathrm{M}$ (MG63 cells), $65.33 \mu \mathrm{M}$ (Saos 2 cells) and $72.38 \mu \mathrm{M}$ (U2OS cells) (Fig. 1C), whereas for the normal cells (HEB and HS5 cells), these values were 286.98 and $366.95 \mu \mathrm{M}$ respectively, which further illustrated the safety of the use of Sch B (Fig. 1D). In addition, it was found that Sch B inhibited the colony formation ability of the $143 \mathrm{~B}$ cells at very low concentrations $(3,6$ and $9 \mu \mathrm{M})$, which indicated that the OS cells were highly sensitive to Sch B, suggesting that it has the ability to inhibit the initiation of OS (Fig. 1E and F). Moreover, Sch B decreased the protein expression levels of PCNA (Fig. $1 \mathrm{G}$ and $\mathrm{H}$ ), which is a recognized marker of cell proliferation. Together, these results indicated that Sch B exerted satisfactory OS cell proliferation inhibitory effects, whilst it did not exert notable toxic effects on normal cells at therapeutic concentrations $(0-100 \mu \mathrm{M})$.

Sch $B$ inhibits the migration and invasion of OS cells. OS metastasis has been associated with a poor prognosis $(3,4)$. Therefore, in the present study, the effects of Sch B on OS cell migration were assessed using wound healing and Transwell assays. In the wound healing assay, the healing rate of the different groups at different time periods was calculated to analyze the inhibitory effects of Sch B on OS cell migration. Compared with the control and DMSO groups, Sch B significantly inhibited OS cell migration in a concentration-dependent manner (Fig. 2A-F). The prominent invasive ability of OS often leads to the destruction of surrounding tissues, which gives rise to the hematogenous metastasis of OS. Herein, Matrigel Transwell invasion assays revealed that Sch B suppressed OS cell invasive potential as well (Fig. 2G and $\mathrm{H}$ ). However, considering that Sch B can effectively inhibit cell proliferation, when the cells exhibit different proliferative 

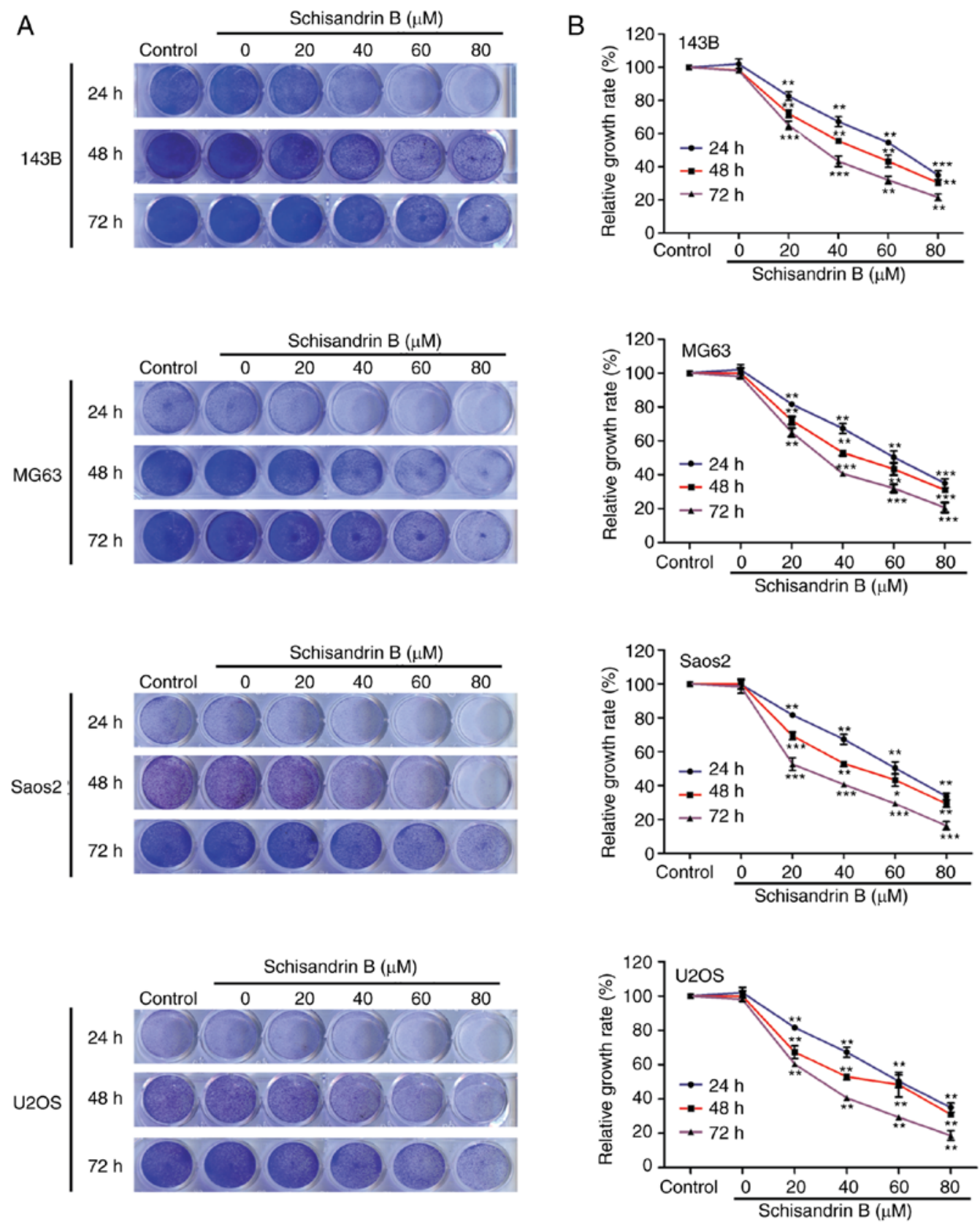

Figure 1. Continued.

abilities under the different experimental conditions, this may affect the study of cell migration and invasion. Therefore, the expression levels of well-known markers of tumor invasion and metastasis were also assessed. Epithelial-mesenchymal transition (EMT) is a biological process in which epithelial cells transform into cells with mesenchymal phenotype through specific procedures (22). EMT is important for tumor invasion and metastasis. The expression of the EMT-related proteins, N-cadherin, Snail and Vimentin, was observed using western blot analysis, and was found to be decreased by Sch B, whereas the opposite effect was observed as regards E-cadherin expression (Fig. 2I and J). MMPs can degrade almost all types of protein components in the extracellular matrix; thus, increasing attention has been given due to their role in destroying the histological barrier (23). Sch B also significantly decreased the expression of MMP-2, MMP-7 and MMP-9 (Fig. 2I and J). Therefore, Sch B may effectively suppress OS cell migration and invasion.

Sch $B$ induces the cell cycle arrest and apoptosis of OS cells. Through flow cytometry analysis, it was revealed that Sch B hindered OS cell mitosis progression in the $G_{1}$ phase (Fig. 3A-D). Therefore, the expression levels of ccyclin D1 and cyclin $\mathrm{E}$ were detected using western blot analysis, and it was demonstrated that the cyclin levels, which promote cell cycle progression from the $G_{1}$ to the $S$ phase, decreased in a concentration-dependent manner (Fig. 3E and F). Following Hoechst 33258 staining, it was observed under a fluorescence microscope that following treatment with Sch B, nuclear pyknosis, nuclear fragmentation and a large number of apoptotic bodies were present in OS cells (Fig. 4A). In addition, flow cytometric analysis for apoptosis, it was demonstrated 

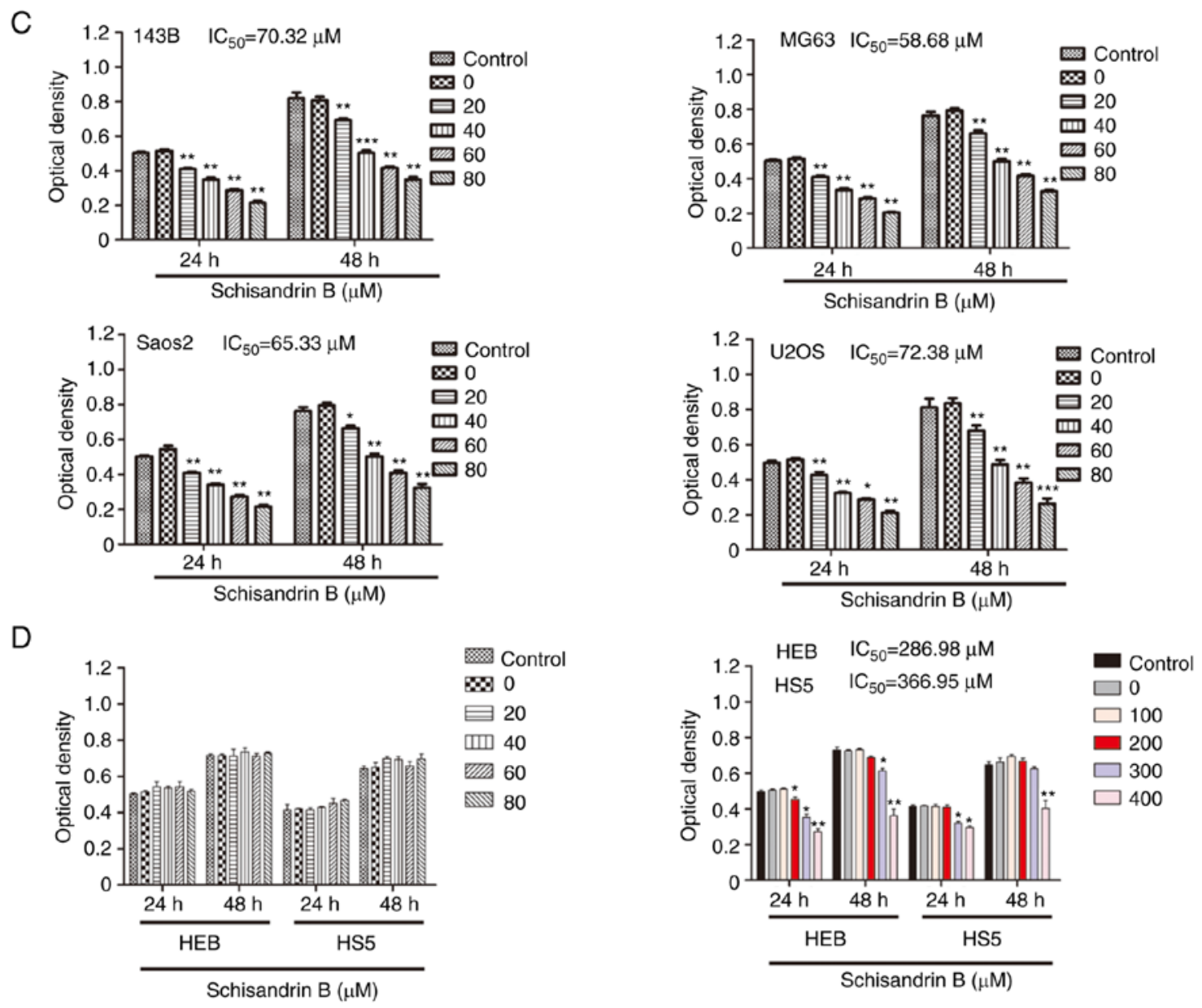

E

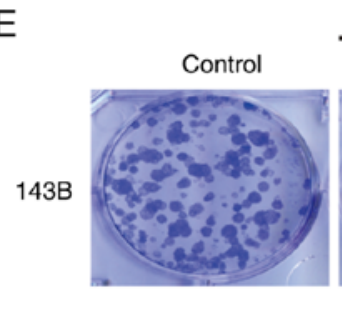

$\mathrm{F}$

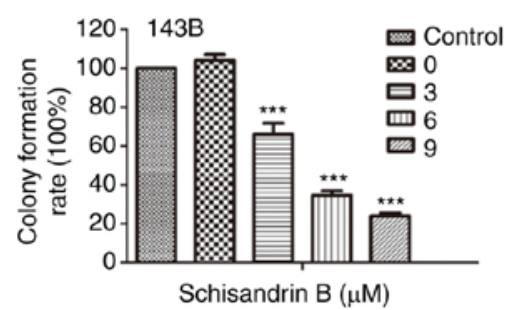

G

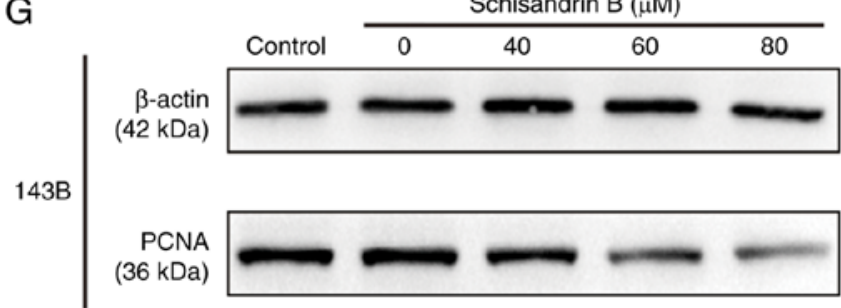<smiles>COc1cc2c(c(OC)c1OC)-c1c(cc3c(c1OC)OCO3)CC(C)C(C)C2</smiles>

Figure 1. (A and B) Inhibitory effect of Sch B on 143B, MG63, Saos2 and U2OS OS cell proliferation was evaluated using crystal violet staining and quantitative analysis. (C) MTT assay was used to detect the effect of Sch B on the viability of OS cells. (D) MTT assay was used to detect the effects of Sch B on the viability of normal HEB and HS5 cells. (E and F) Colony formation assay and quantitative analysis was used to detect the effect of Sch B on the proliferation of OS cells. ( $\mathrm{G}$ and $\mathrm{H}$ ) Western blot analysis revealed that Sch B decreased the expression of PCNA in 143B OS cells. (I) Chemical structure of Sch B. "P<0.05, ${ }^{* * *} \mathrm{P}<0.01,{ }^{* * *} \mathrm{P}<0.001$ vs. control group; $\mathrm{n}=3$. Sch B, Schisandrin B; OS, osteosarcoma; PCNA, proliferating cell nuclear antigen. 
A
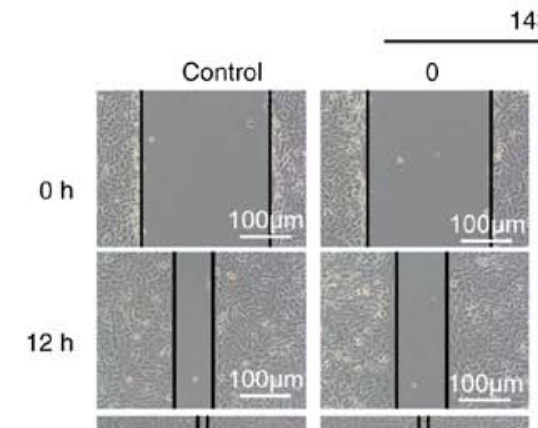

$143 B$

Schisandrin B $(\mu \mathrm{M})$

$24 \mathrm{~h}$
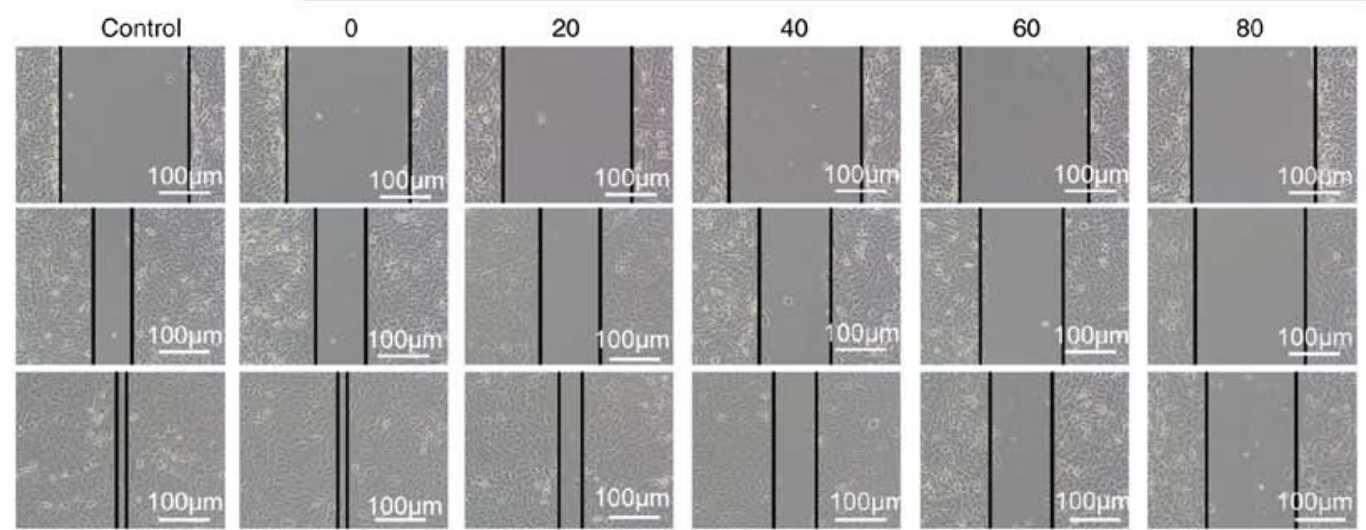

B
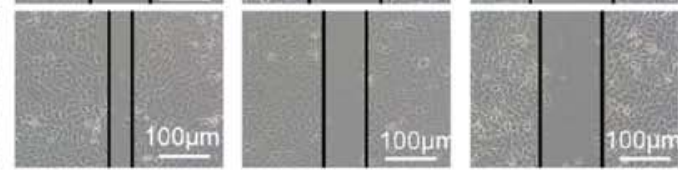

Schisandrin B $(\mu \mathrm{M})$

MG63
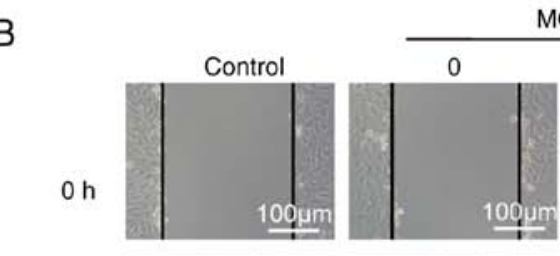

$12 \mathrm{~h}$
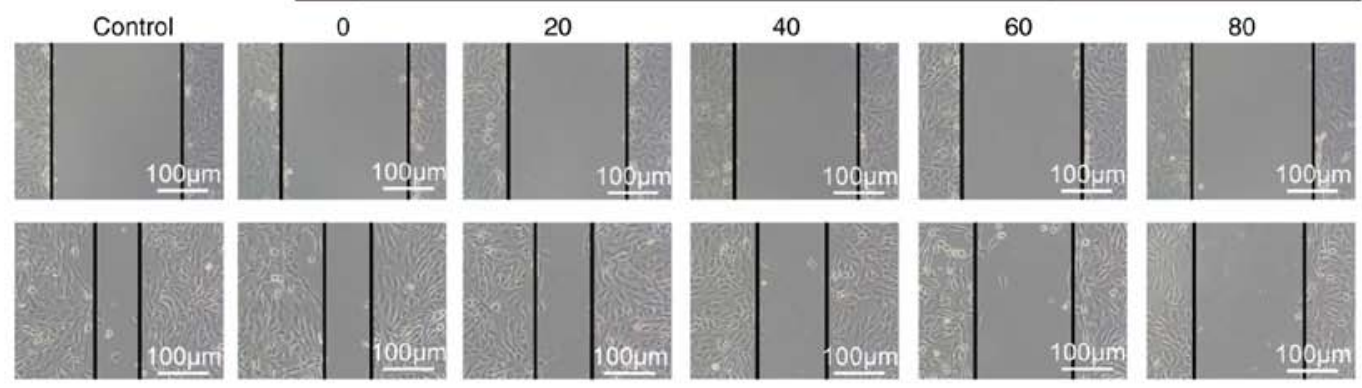

$24 \mathrm{~h}$
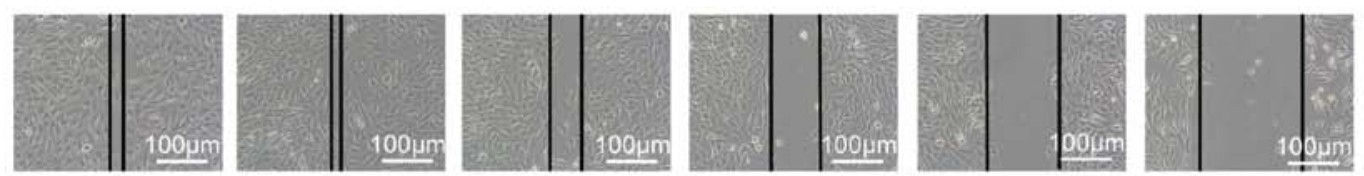

C

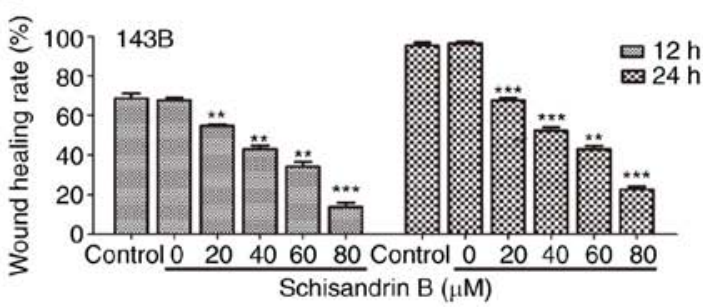

D

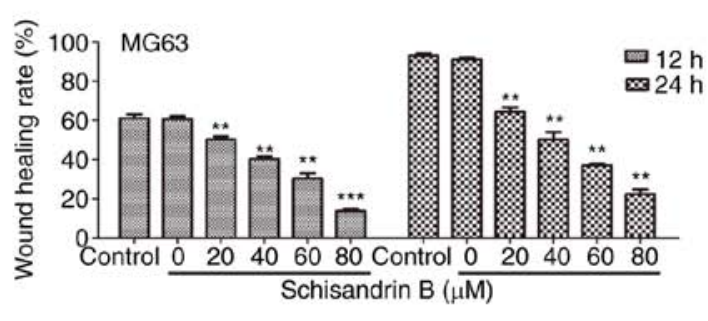

Figure 2. Continued.

that Sch B significantly increased the OS cell apoptotic rate, particularly that of late apoptosis (Fig. 4B-E). In order to explore the molecular mechanisms underlying the promoting effects of Sch on the apoptosis of OS cells, the expression of a large number of apoptosis-related proteins was assessed. It was observed that Sch B increased the expression of certain apoptosis-promoting proteins, including the $\mathrm{Bcl}-2$ protein family members Bad and Bax. However, Sch B decreased Bcl-2 expression. Moreover, the expression of the apoptotic biomarkers, cleaved caspase-3, PARP and cleaved PARP was increased following treatment with $\mathrm{Sch} \mathrm{B}$, and the expression of caspase-3 decreased (Fig. 4F and G).

Sch B exerts its effects on OS cells via the Wnt/B-catenin and PI3K/Akt signaling pathways. In order to examine the mechanisms underlying the inhibitory effects of Sch B on OS cells, the drug-disease gene interactions of Sch B and OS were determined using network pharmacological analysis (Fig. 5A), and the target protein network was visualized (Fig. 5B), so as to screen the top 30 key genes (Fig. 5C). Then the relevant signal pathways were determined by GO function annotation and KEGG pathway enrichment analysis (Fig. 5D and E). It was found that the core targets may be located in the Wnt/ $\beta$-catenin and PI3K/Akt signaling pathways.

Subsequently, the changes in key targets in related signaling pathways were assessed using western blot analysis. It was observed that Sch B primarily altered the key targets of the Wnt/ $\beta$-catenin and PI3K/Akt signaling pathways in OS cells. The Wnt/ $\beta$-catenin signaling pathway plays a crucial role in early development, organ formation, tissue regeneration and other physiological processes during animal embryonic development. If the key proteins in this signaling pathway mutate, this may culminate in an abnormal signal activation, possibly inducing cancer occurrence (24). In the present study, the components and downstream targets of the Wnt/ $\beta$-catenin signaling pathway were examined using western blot analysis. 
E

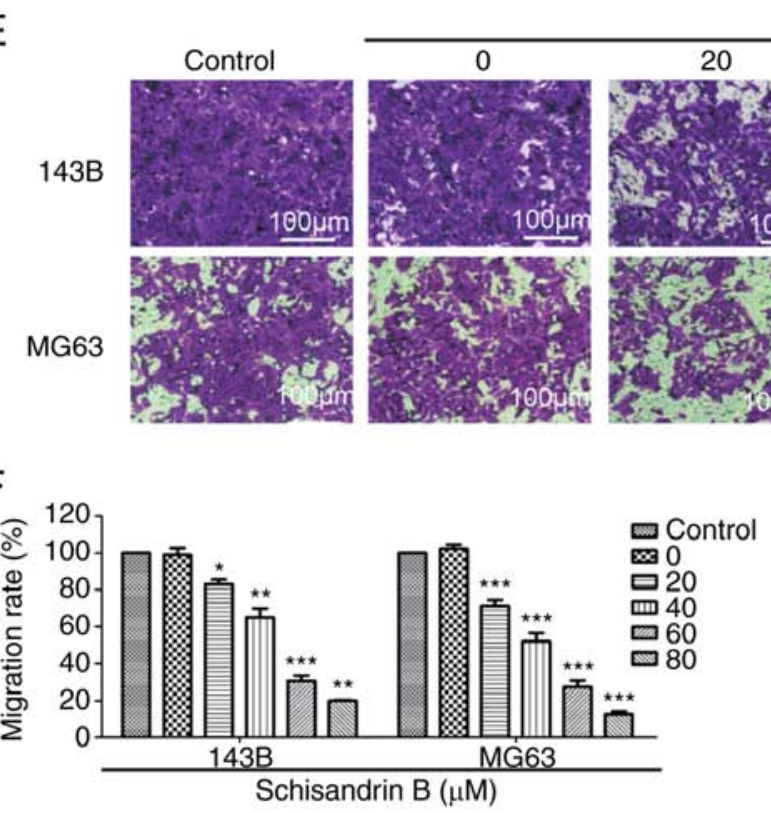

Schisandrin $\mathrm{B}(\mu \mathrm{M})$

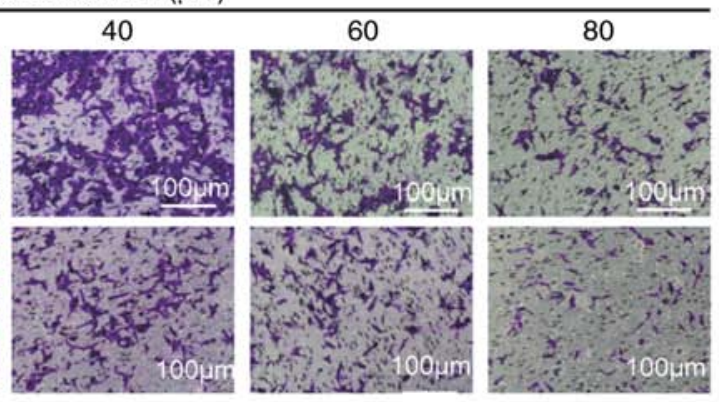

$\mathrm{H}$
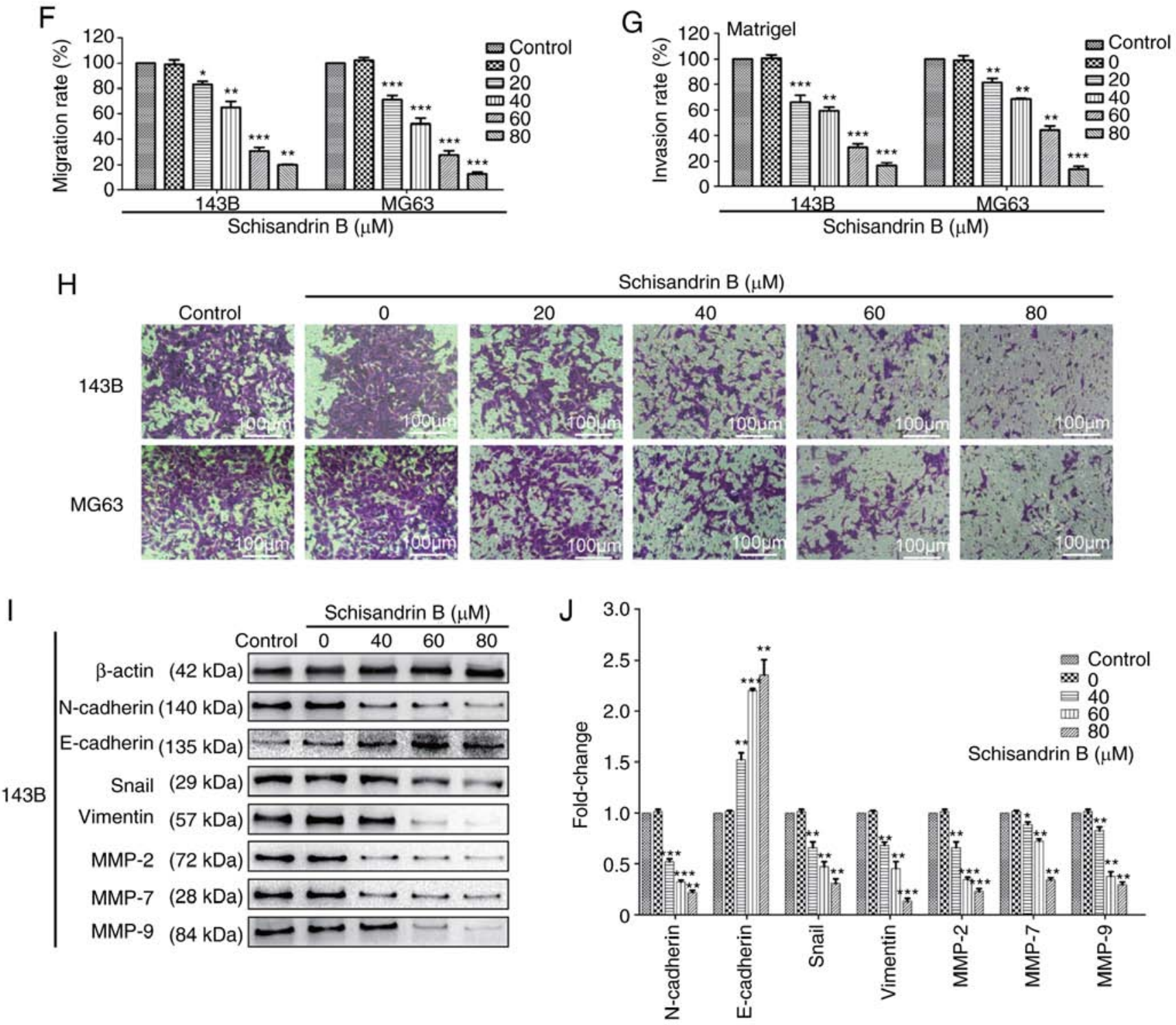

Figure 2. (A-D) Wound healing, and (E and F) Transwell migration assays revealed that Sch B inhibited the migration of 143B and MG63 OS cells. $(\mathrm{G}$ and $\mathrm{H})$ Matrigel Transwell invasion assays revealed that Sch B suppressed 143B and MG63 OS cell invasive potential. (I and J) Western blot analysis was used to detect the effects of Sch B on the expression of migration- and invasion-related proteins, including MMP-2, MMP-7, MMP-9, N-cadherin, E-cadherin Snail and Vimentin. ${ }^{*} \mathrm{P}<0.05,{ }^{* *} \mathrm{P}<0.01,{ }^{* * *} \mathrm{P}<0.001$ vs. control group; $\mathrm{n}=3$. Sch $\mathrm{B}$, Schisandrin B; OS, osteosarcoma; MMP, matrix metalloproteinase.

The results revealed that compared with the control group, the expression of $\beta$-catenin, the core member of the Wnt $/ \beta$-catenin signaling pathway, was decreased, whereas that of GSK-3 $\beta$, a negative regulator of the $\mathrm{Wnt} / \beta$-catenin signaling pathway, was significantly increased in the OS cells treated with Sch B. In addition, the expression of c-Myc, the target gene of Wnt, was also significantly decreased (Fig. 6A and B). As an important signal transduction pathway, the PI3K/Akt signaling pathway plays a key role in inhibiting the apoptosis and promoting the proliferation of cells by affecting the activation of downstream effector molecules $(25,26)$. It is closely related to the occurrence and development of various human tumors (27). Herein, western blot analysis revealed that the expression levels of the PI3K/Akt signaling pathway-related proteins, Akt, p-Akt 

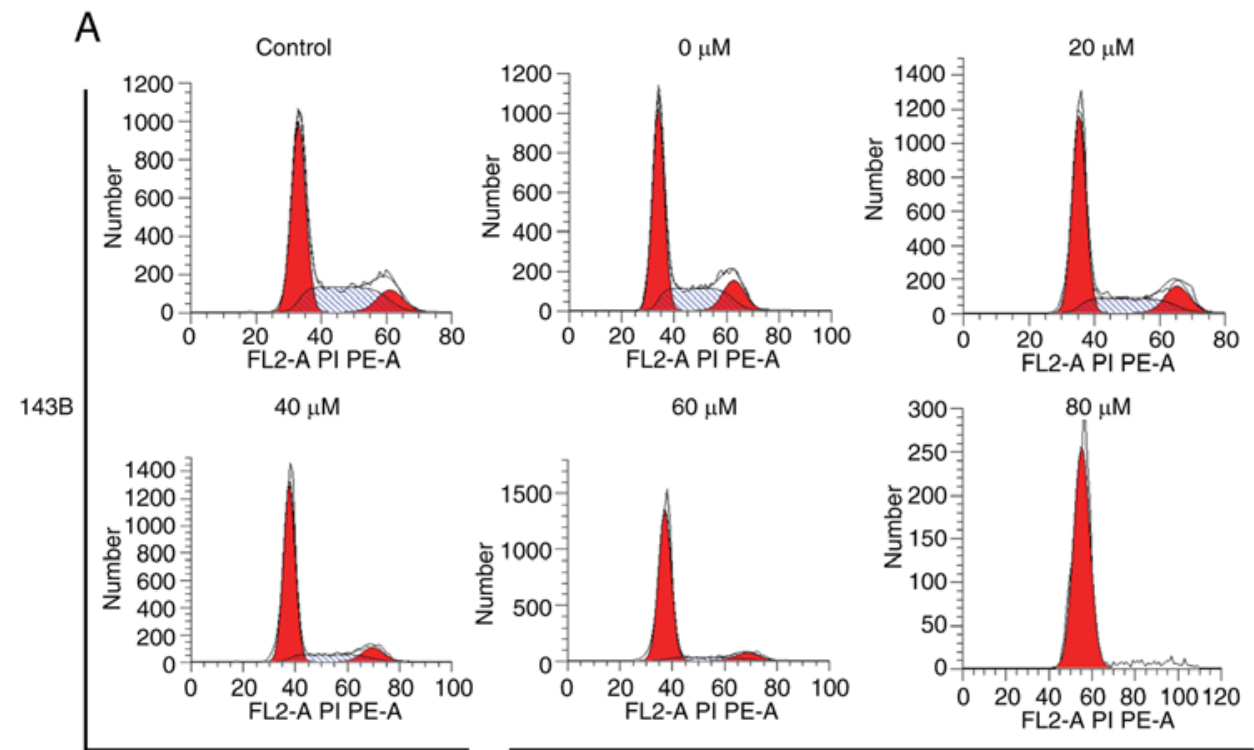

B
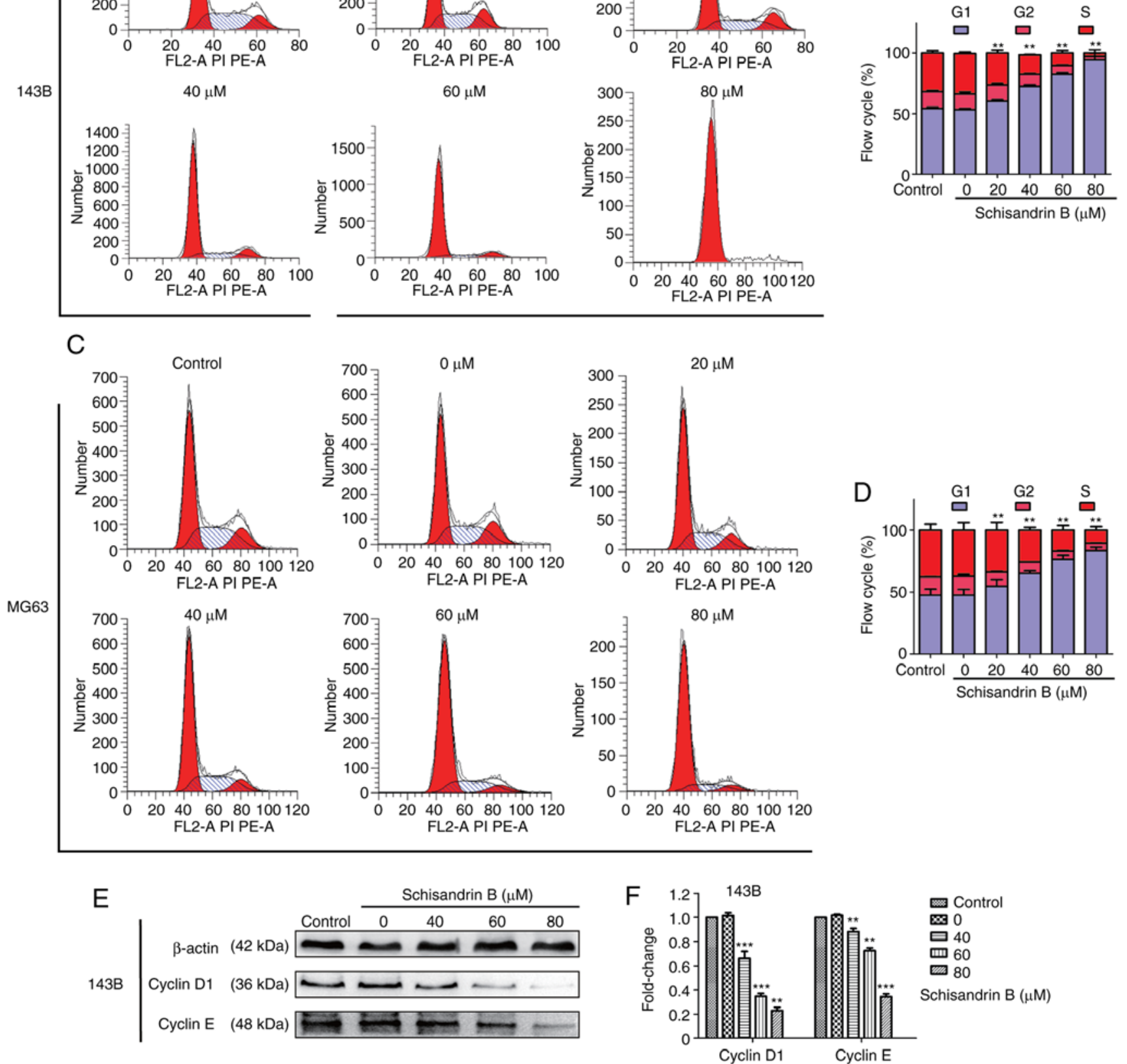

Figure 3. (A-D) Flow cytometric analysis demonstrated that Sch B arrested the 143B and MG63 osteosarcoma cells in the $\mathrm{G}_{1}$ phase. (E and F) Western blot analysis demonstrated that cyclin $\mathrm{D} 1$ and cyclin $\mathrm{E}$ expression, which promote the progression of the cell cycle from the $\mathrm{G}_{1}$ to $\mathrm{S}$ phase, was decreased, following treatment with Sch B. ${ }^{* *} \mathrm{P}<0.01,{ }^{* * *} \mathrm{P}<0.001$ vs. control group; $\mathrm{n}=3$. Sch B, Schisandrin B.

(Ser473) and p-Akt (Thr308), were all decreased in the OS cells following treatment with Sch B (Fig. 6A and B). In order to further confirm that the changes in the protein expression levels of the targets in the related signaling pathways were involved in the effects of Sch B on OS cells, the cells were treated with the Wnt signaling pathway agonist, BML284, and the Akt phosphorylation activator, SC79, in combination with Sch B. Both BML284 and SC79 partially reversed the anticancer effects of Sch B on OS cells (Fig. 6C-K). Taken together, the anticancer effects of Sch B on OS cells were demonstrated to be related to Wnt/ $\beta$-catenin and PI3K/Akt signaling pathway inhibition.

Sch B inhibits tumor growth and lung metastasis in vivo. An in vivo $\mathrm{OS}$ model was established to further examine the effects of Sch B on the growth and metastasis of OS. The results revealed that Sch B inhibited OS growth in a dose-dependent manner, and the body weight of the mice in each group did 

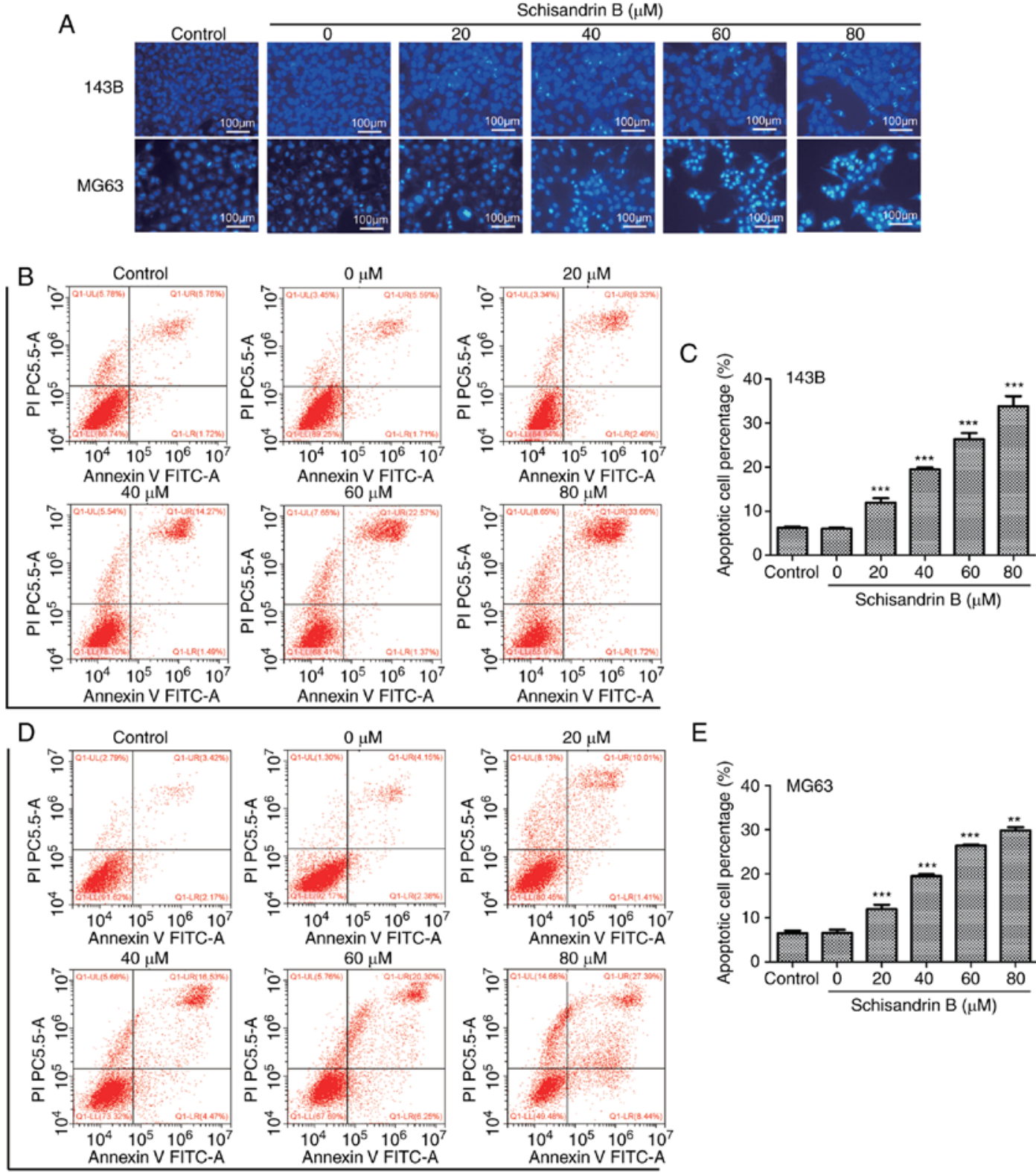

$\mathrm{E}$

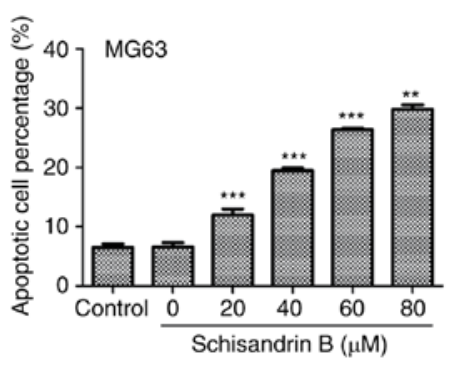

$\mathrm{F}$
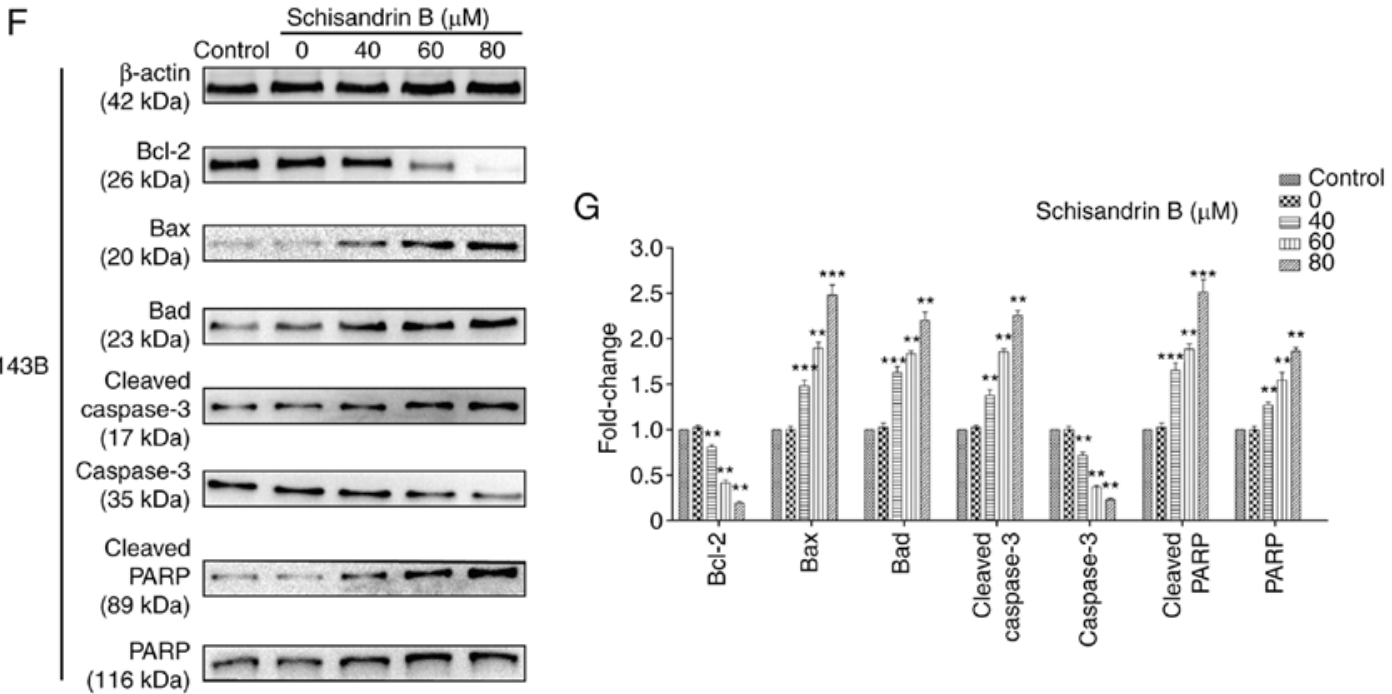

Figure 4. (A-E) Hoechst 33258 staining revealed that Sch B promoted OS cell apoptosis in a concentration-dependent manner and flow cytometric analysis of apoptosis revealed that Sch B significantly increased the apoptotic rate of OS cells, particularly the proportion of cells in late apoptosis. (F and G) Expression of Bad, Bax, Bcl-2, caspase-3, cleaved caspase-3, PARP and cleaved PARP were detected using western blot analysis. ${ }^{* *} \mathrm{P}<0.01,{ }^{* * *} \mathrm{P}<0.001$ vs. control group; $\mathrm{n}=3$. Sch B, Schisandrin B; OS, osteosarcoma; PARP, poly(ADP-ribose) polymerase. 

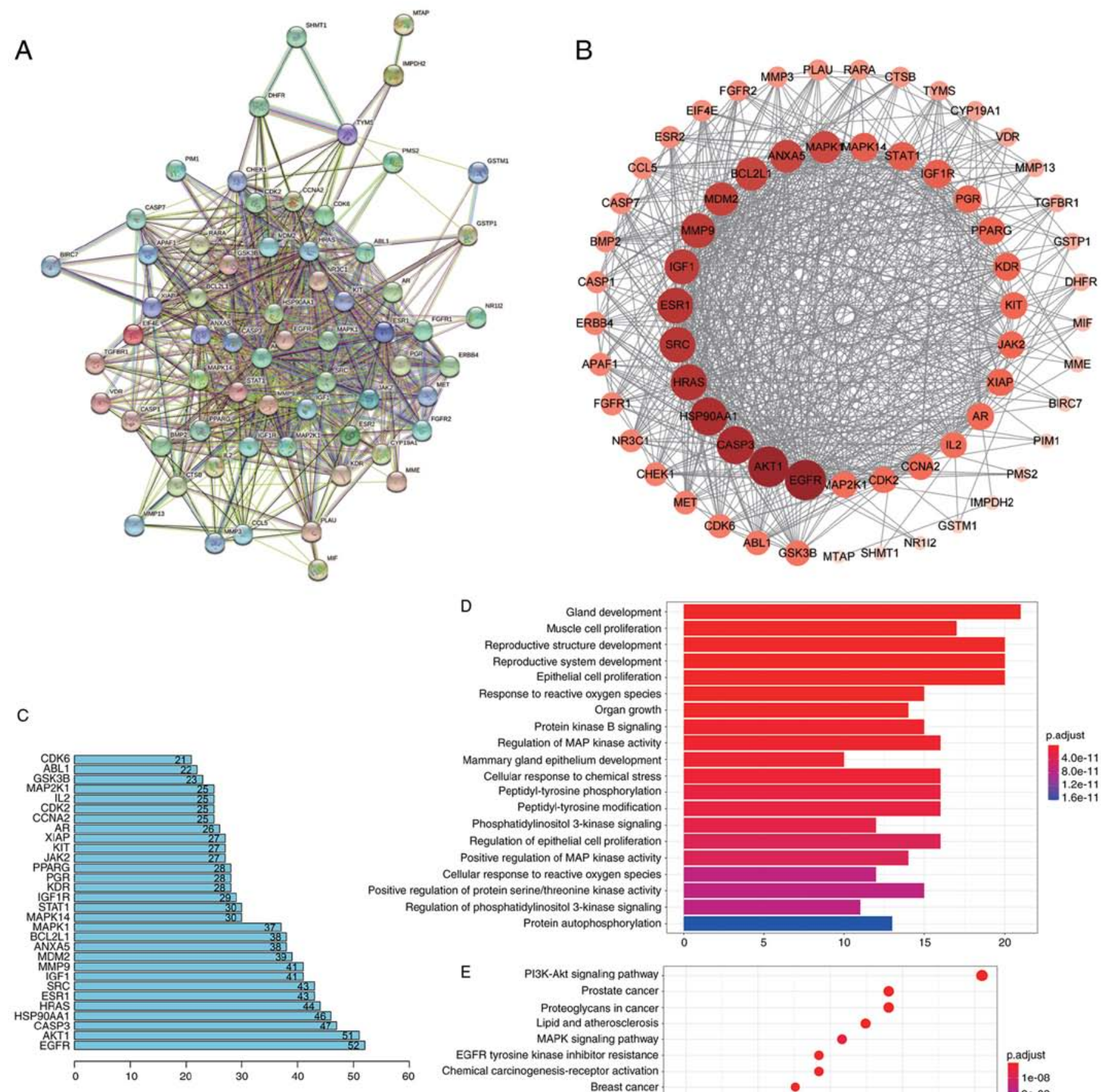

D
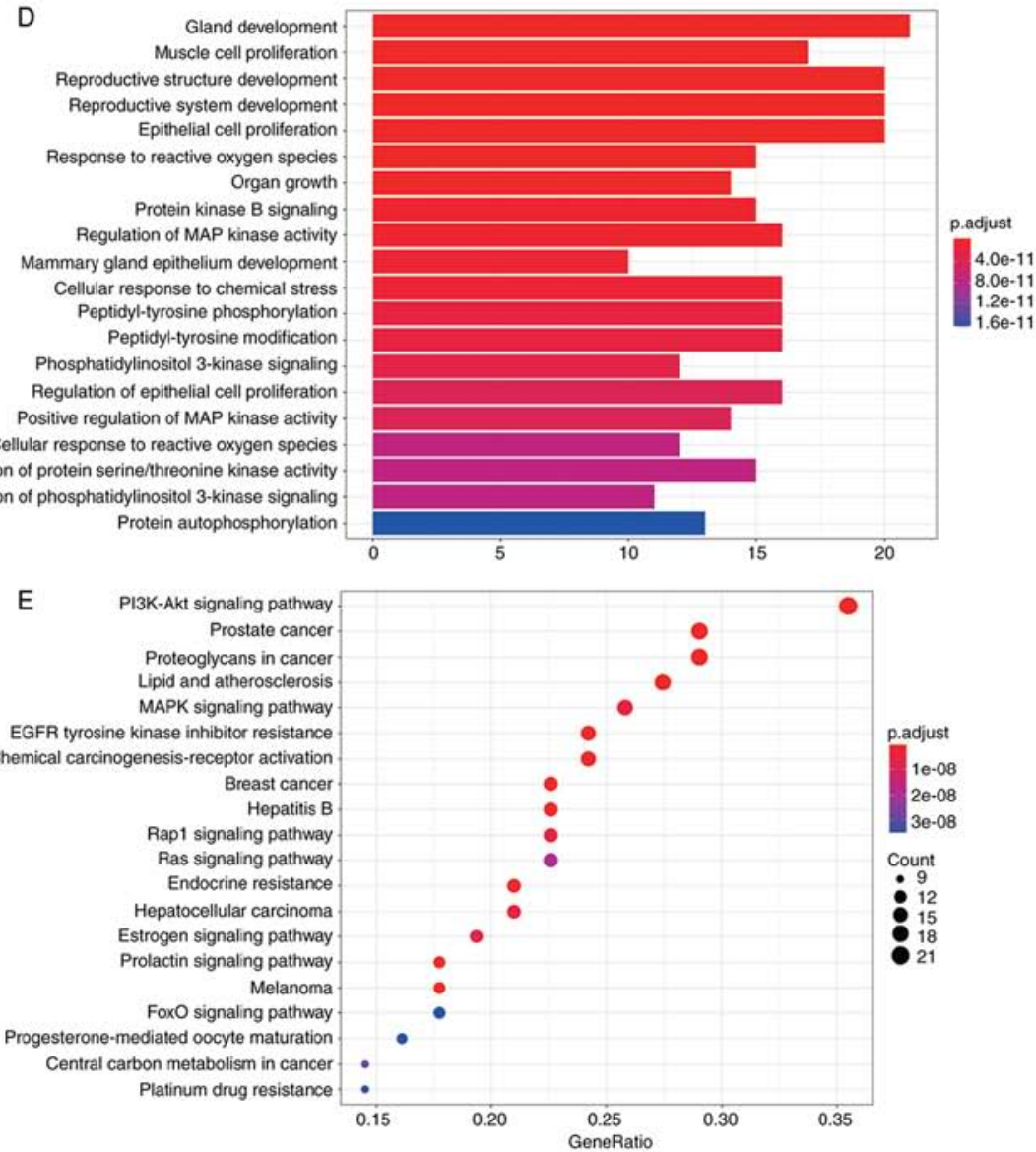

Figure 5. (A) Network pharmacological analysis of Sch B. Protein interaction network of Sch B in the treatment of OS. (B) Target protein regulatory network of Sch B in the treatment of OS. (C) Key genes and degree value (top 30) of Sch B in the treatment of OS. (D) GO enrichment analysis of Sch B in the treatment of OS. (E) KEGG pathway analysis of Sch B in the treatment of OS. Sch B, Schisandrin B; OS, osteosarcoma; GO, Gene Ontology; KEGG, Kyoto Encyclopedia of Genes and Genomes.

not change significantly during the administration period (Fig. 7A-C). Using H\&E staining, it was demonstrated that compared with the control group, the tumor nuclear heterogeneity in the treatment group was reduced; conversely, nuclear fragmentation and nucleolysis were increased. In addition, the tumor tissue in the treatment group became 

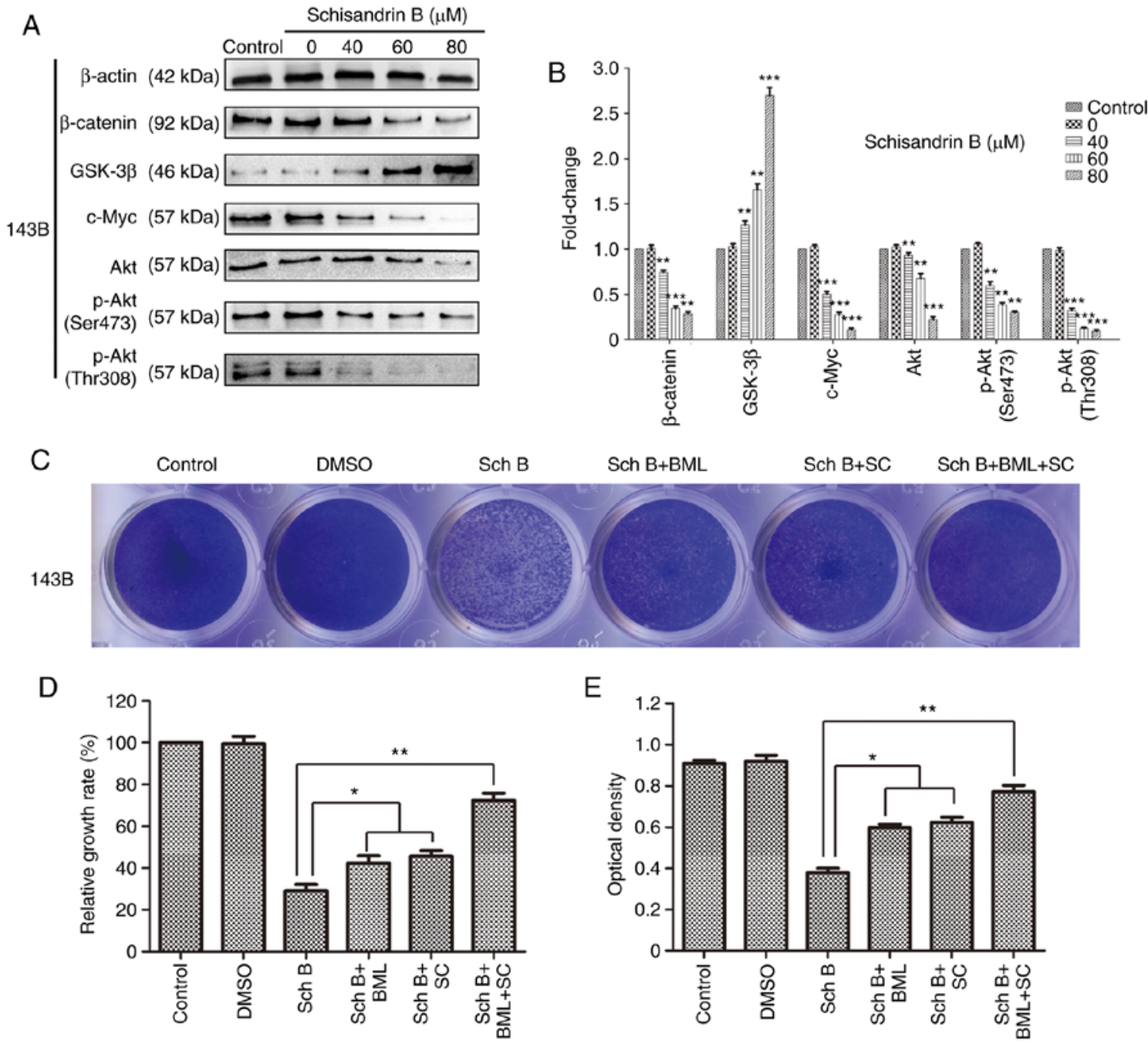

Figure 6. Continued.

significantly more detached (Fig. 7D). Immunohistochemical results demonstrated that the expression levels of PCNA, Bcl-2, Vimentin, $\beta$-catenin and p-Akt (ser308) were significantly decreased when treated with a high Sch B concentration, in accordance with the in vitro results (Fig. 7E). As regards OS metastasis inhibition in vivo, dense and heterogeneous cell masses were observed in the mouse lung tissue in the control group, suggesting the lung metastasis of OS; however, similar cell masses could not be observed in the high Sch B concentration treatment group. Sch B effectively reduced the tumor mass in the lungs according to lung H\&E staining (Fig. 7F). Thus, these results suggested that Sch B inhibited OS growth and lung metastasis in vivo.

\section{Discussion}

OS is well known for its high malignancy capacity and early occurrence of distant metastasis. The reported high OS incidence in children and adolescents is accompanied by severe burdens for families and society (1). At present, surgery combined with chemotherapy is the primary treatment option for OS, including neoadjuvant chemotherapy prior to surgery and adjuvant chemotherapy following surgery (28). Although the emergence of neoadjuvant chemotherapy has improved the 5-year survival rate of patients with OS, the use of common chemotherapeutic drugs, including adriamycin, methotrexate and cisplatin results in severe side-effects, such as congestive heart failure induced by adriamycin interfering with the structure and function of mitochondria in tumor cells, greatly affecting the quality of life of patients $(29,30)$. In addition, the development of resistance to chemotherapeutic drugs in the treatment of OS also brings additional challenges to the treatment of OS (30). Therefore, it is of utmost importance to identify novel and safe drugs for the treatment of OS.

The characteristics of multi-targeting traditional Chinese medicine extracts with fewer and less severe side-effects in the treatment of tumors has attracted increased attention (32). Amongst these agents, Sch B has been shown to exert therapeutic effects in a variety of malignant tumors, and recent reports have demonstrated that Sch B may inhibit osteoclast formation and function, highlighting Sch B as a potential drug for OS treatment (7-11,33). In the present study, it was revealed that $\mathrm{Sch}$ B exerted inhibitory effects on OS in vitro and in vivo via Wnt/ $\beta$-catenin and PI3K/Akt signaling pathway regulation; SchB inhibited the proliferation, migration and invasion, and promoted the apoptosis of OS cells; it also inhibited the tumor growth and reduced the lung metastasis of OS in vivo. 

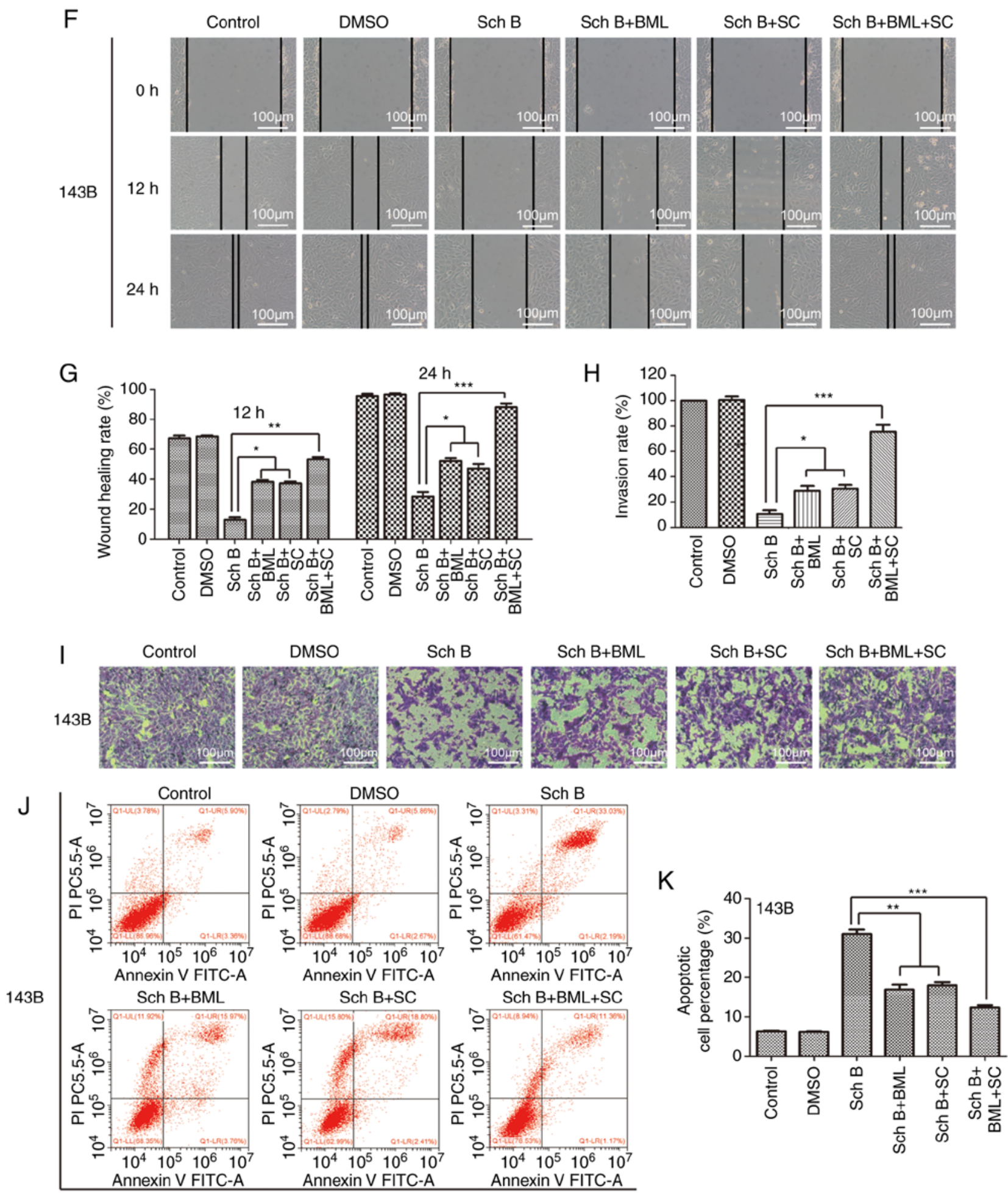

Figure 6. Sch B exerts its effects on OS cells through the regulation of the Wnt/ $/$-catenin and PI3K/Akt signaling pathways. The Wnt signaling pathway agonist, BML284, and the Akt phosphorylation activator, SC79, partially reversed the antitumor effects of Sch B. (A and B) Western blot analysis was used to detect the expression of related proteins, including $\beta$-catenin, GSK-3 $\beta$, c-Myc, Akt, p-Akt (Ser473) and p-Akt (Thr308) in 143B OS cells treated with Sch B. ${ }^{*} \mathrm{P}<0.05,{ }^{* *} \mathrm{P}<0.01$ and ${ }^{* * *} \mathrm{P}<0.001$ vs. the control group. $\mathrm{n}=3$. (C-K) The Wnt signaling pathway agonist, BML284, and the Akt phosphorylation activator, SC79, partially reversed the inhibitory effects of Sch B on 143B OS cell proliferation, migration and invasion, and suppressed the high rate of apoptosis induced by Sch B. ${ }^{*} \mathrm{P}<0.05,{ }^{* * *} \mathrm{P}<0.01,{ }^{* * *} \mathrm{P}<0.001$ vs. the Sch B group; $\mathrm{n}=3$. Sch B, Schisandrin B; OS, osteosarcoma; p-, phosphorylated.

The inhibition of excessive tumor cell proliferation is the primary issue required to be addressed for the treatment of malignant tumors. In the present study, by conducting a series of cell proliferation-related experiments, it was demonstrated that Sch B inhibited the proliferation of OS cells in a concentration-dependent manner, and it had no obvious toxic effects on normal cells at the therapeutic concentrations used $(0-100 \mu \mathrm{M})$. For the normal cells (HEB and HS5 cells), the $\mathrm{IC}_{50}$ values were 286.98 and $366.95 \mu \mathrm{M}$ respectively. In addition, colony formation assays, which were used to detect the 
A

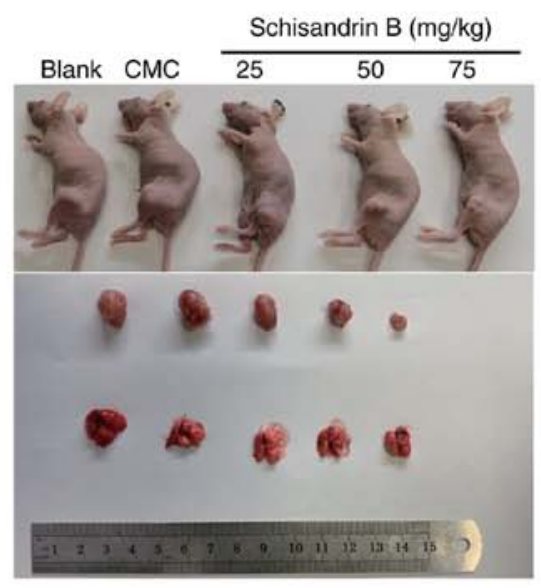

D

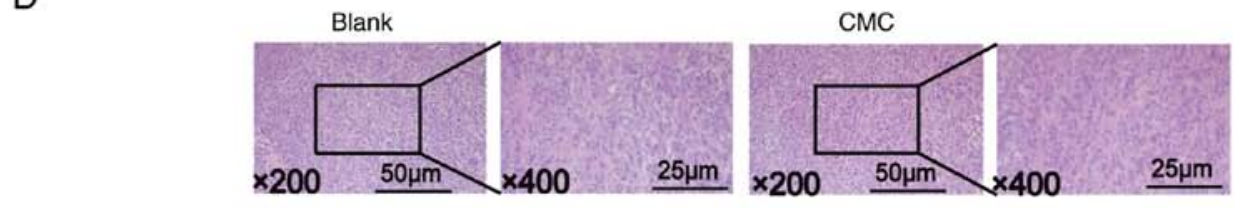

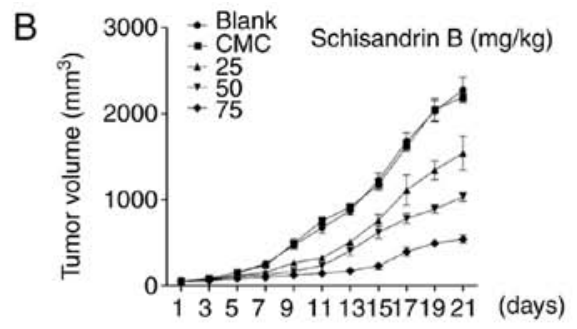

C

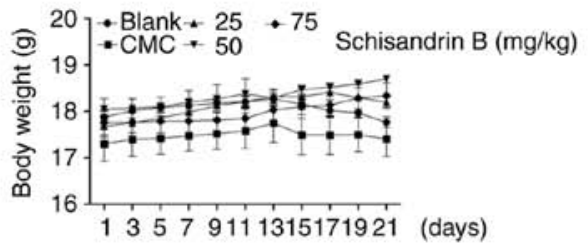

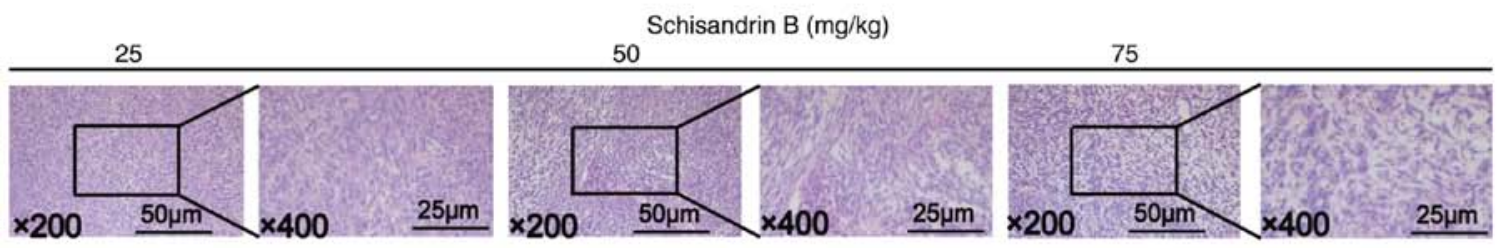
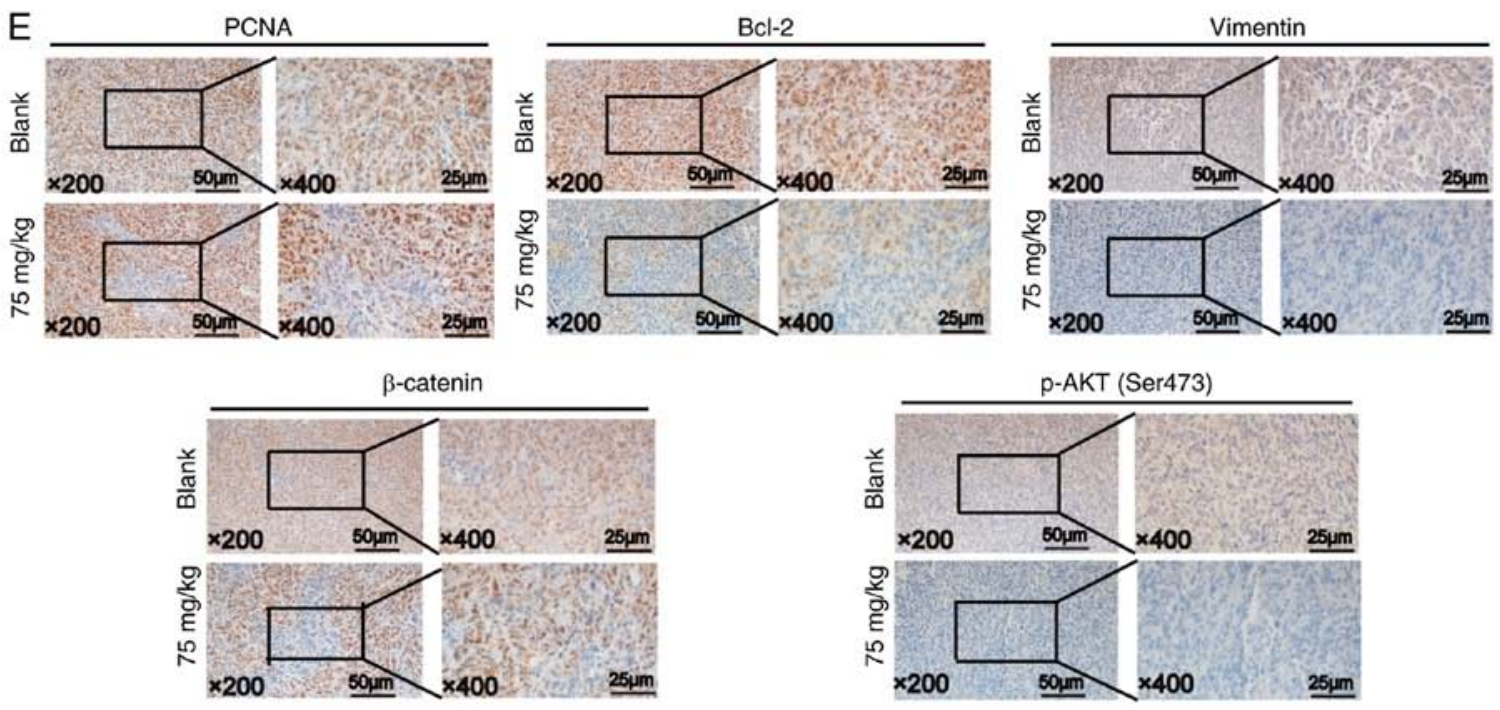

$\mathrm{F}$
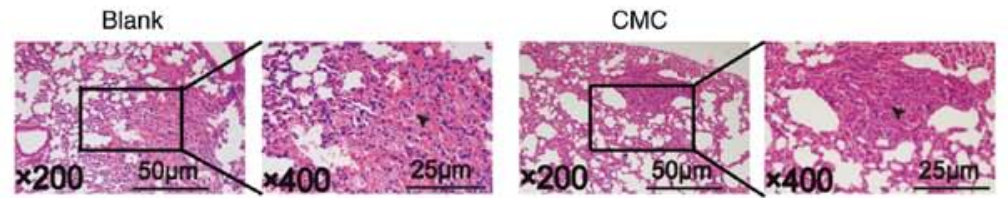

Schisandrin B $(\mathrm{mg} / \mathrm{kg})$
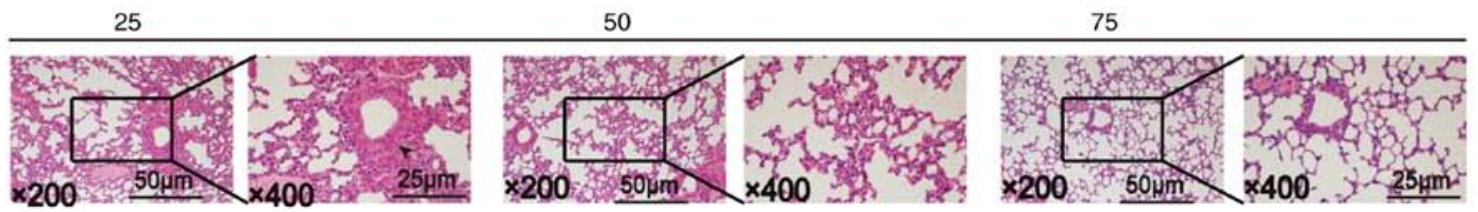

Figure 7. (A) Animal models of OS were established to detect the effect of Sch B on the growth of OS in vivo. (B and C) Changes in tumor size and body weight during Sch B treatment. (D) H\&E staining was used to detect the effects of Sch B on tumor morphology. (E) PCNA, Bcl-2, N-cadherin, $\beta$-catenin and p-Akt (Ser473) were detected using immunohistochemistry. (F) Effects of Sch B on lung metastasis of OS were detected using immunohistochemistry. Sch B, Schisandrin B; OS, osteosarcoma; PCNA, proliferating cell nuclear antigen; p-, phosphorylated. 
sensitivity of OS cells to Sch B, revealed that Sch B inhibited OS cell colony production at a concentration far lower than the one required for the inhibition of OS cell proliferation, thus suggesting that OS cells are highly sensitive to Sch B, and that it may have the potential to inhibit OS initiation $(34,35)$. Furthermore, PCNA plays a central role in promoting DNA replication. It provides a molecular platform, promoting a variety of protein-protein and protein-DNA interactions at the replication fork (36). In OS, the proliferation of OS cells is necessary for rapid progression, whether in the primary site or in the metastatic site. Compared with other signaling pathways, PCNA is an indispensable factor in DNA replication, which is unlikely to be bypassed by resistance mechanisms frequently acquired in chemotherapy treated tumors. Therefore, the inhibition of PCNA is considered to be a feasible anticancer strategy (37). In the present study, the results of western blot analysis revealed that Sch B effectively decreased PCNA expression in OS cells, further highlighting the inhibitory effects of Sch B on OS cell proliferation.

OS has a high mortality rate due to its high rate of metastasis, mainly referring to lung metastasis. Although neoadjuvant chemotherapy improves the 5-year survival rate of patients with localized OS from $20 \%$ to $>65 \%$, the outcome of patients with metastases remains poor (38). In the present study, using wound healing and Transwell assays, it was revealed that Sch B effectively inhibited OS cell migration and invasion. EMT is the basic process required by the initial and subsequent events in the process of embryogenesis (39). It has been previously reported that when cancer stem cells begin undergoing EMT, the cancer-derived mesenchymal cells are invasive, and these cells thus exhibit metastatic activity (40). Snail has been reported to play a key role in the regulation of EMT, being considered a key regulatory node in the transcriptional activation of EMT (41). Snail has been also demonstrated to inhibit E-cadherin transcription, which encodes epithelial cell-specific proteins, further promoting cell adhesion junction degradation (42). During this process, E-cadherin is replaced by $\mathrm{N}$-cadherin, and epithelial cells have been reported to obtain the characteristics of high mesenchymal cell fluidity, thus being able to provide increased flexibility in cell migration and invasion (43). Furthermore, it has been previously reported that the cytokeratin cytoskeleton may be transformed into a Vimentin-dominated cytoskeleton, including also the morphological characteristics of mesenchymal cells $(44,45)$. EMT has been reported to be involved in the invasion and migration of tumor cells through a dense collagen-rich extracellular matrix surrounding the tumor. MMPs inhibit or enhance tumor invasion by destroying the dynamic balance of extracellular matrix (46). Western blotting revealed that Sch B could inhibit OS cell migration and invasion by inhibiting EMT. In addition, it has been demonstrated that Sch B inhibits osteoclastogenesis (33). In primary bone cancer and metastasis, the process of bone remodeling creates a favorable environment for the establishment and progression of tumors. In this environment, osteoclasts mediate the destruction of inorganic bone components and collagen dissolution, providing an opportunity for distant metastasis of primary OS, particularly for hematogenous metastasis (47). Therefore, Sch B may inhibit OS metastasis not only by reducing migration- and invasion-related OS cell protein expression, but by also participating in physiological bone remodeling process hijacked by OS.
Cell cycle arrest is considered to be an important, however closely related to apoptosis factor, affecting cell proliferation. Cell cycle arrest leads to apoptosis by increasing the frequency and/or degree of DNA damage, or by reducing the ability of DNA damage repair mechanisms in cells. In this process, cell cycle arrest has dual significance: Not only does it provide a window of opportunity for the repair of damaged DNA, but it also increases the time and probability for the repair system of DNA to be exposed to exogenous harmful stimuli (if the harmful factor is toxic to DNA and/or its repair system). The result of the contest between these two factors ultimately determines the final fate of cells (48-50). In the present study, using flow cytometric analysis, it was revealed that Sch B blocked OS cell cycle progression in the $G_{1}$ phase, and western blot analysis revealed that the expression of cyclin D1 and cyclin E decreased in a concentration-dependent manner. Cyclin D1 modulates the transition from the $G_{1}$ to the $S$ phase through its action as an allosteric regulator of CDK4 and CDK6. The upregulated expression of cyclin D1 culminates in unchecked cellular proliferation, thereby promoting tumor growth (51). Cyclin E, a regulatory subunit of $\mathrm{CDK} 2$, has been considered to be integral for the initiation of DNA replication at the $\mathrm{G}_{1} / \mathrm{S}$ checkpoint (52). Therefore, the mechanisms through which Sch B blocks OS cell cycle progression in the $G_{1}$ phase were fund to involve the reduction in cyclin D1 and cyclin E expression. Similarly, flow cytometric analysis demonstrated that Sch B promoted OS cell apoptosis in a concentration-dependent manner, particularly in the late stages. In mammals, two primary pathways have evolved for activating the caspase cascade, namely, the mitochondrial pathway (intrinsic pathway) and the death receptor pathway (extrinsic pathway). In the endogenous apoptotic pathway, mitochondrial outer membrane permeability is primarily regulated by Bcl-2 family members, including anti-apoptotic protein (Bcl-2) and pro-apoptotic proteins (Bax and Bad) (53). When subjected to a decrease in Bcl-2 and an increase in Bax and Bad levels, mitochondria have been revealed to be stimulated to release cytochrome $c$, subsequently activating caspase-3, and ultimately leading to apoptosis. The most important substrate of caspase-3 is PARP. The activation of caspase- 3 leads to the over-activation of PARP, consuming intracellular NAD ${ }^{+}$, reducing intracellular ATP levels and eventually resulting in cell death (54). Herein, using western blot analysis, it was shown that the expression levels of cleaved caspase-3, PARP and cleaved PARP were increased in OS cells treated with Sch B, and the expression level of caspase-3 decreased. In addition, amongst the $\mathrm{Bcl}-2$ family member proteins, the expression of the anti-apoptotic protein, Bcl-2 decreased, whereas that of the pro-apoptotic proteins, Bax and Bad, increased. It was thus revealed that $S c h$ B blocked OS cell cycle progression in the $G_{1}$ phase and promoted apoptosis.

The Wnt pathway has been reported to be important for the control of embryonic bone development, bone integrity and postnatal bone regeneration. In addition, The Wnt signaling pathway has been shown to be closely associated with OS (55). Four Wnt signaling pathways have been described thus far: The Wnt/ $\beta$-catenin pathway, the Wnt/Ca ${ }^{2+}$ pathway, the Wnt/planar cell polarity (Wnt/PCP) pathway and the Wnt/protein kinase A (Wnt/PKA) pathway. The Wnt/ $\beta$-catenin pathway has been widely studied, particularly with regard to its association with tumor development. When cells are not stimulated by a 
Wnt signal, most of the $\beta$-catenin in the cytoplasm binds with cadherin protein on the cell membrane to make it adhere to the cytoskeletal protein actin and participate in cell adhesion. In the presence of the appropriate Wnt ligands, the binding of Wnt to its receptor complex leads to the activation of intracellular protein Disheveled (DVL). DVL can stabilize the free state of $\beta$-catenin protein in the cytoplasm by inhibiting the degradation activity of the $\beta$-catenin degradation complex formed by GSK3- $\beta$ and other proteins. After the stable accumulation of $\beta$-catenin in the cytoplasm entering the nucleus, it binds to the $\mathrm{TCF} / \mathrm{LEF}$ transcription factor family members and initiates the transcription of downstream target genes (including -Myc and Cyclin D1), ultimately leading to abnormal cell proliferation and cell cycle transition, and in turn promoting tumor formation (55-57). In the present study, it was demonstrated that Sch B also inhibited the PI3K/Akt signaling pathway to play an inhibitory role in OS. Akt, also known as protein kinase $\mathrm{B}$, is a $57-\mathrm{kDa}$ serine/threonine kinase and is the central node of several signaling pathways, and has often been reported to be deregulated in numerous types of human cancer (58). The upstream activator phosphoinositide-dependent kinase 1 phosphorylates Akt at Thr308, resulting in partial activation of Akt. Ser473 is phosphorylated by the mechanistic target of rapamycin complex 2, which can stimulate the complete enzymatic activity of Akt (59). Therefore, Akt can be dephosphorylated and its activation reduced, preventing all downstream signal transduction events regulated by Akt, and thus regulating cell proliferation, differentiation, apoptosis and migration. In the present study, Sch B downregulated the expression of p-Akt (Ser473) and p-Akt (Thr308) in OS cells concurrently, which was different from the previous single inhibition of p-Akt isoforms $(60,61)$.

In the present study, all cells were treated when the cell density reached 50\%; although tumor cells have a strong clonal growth ability, they still have a certain population. This is due to the interdependence between tumor cells. If these dependencies are eliminated or weakened, the activity of cancer cell proliferation and growth may be affected. When the cell density is $\sim 50 \%$, it suggests that the tumor cells are in the exponential growth period and have a strong proliferation and growth activity. Therefore, the addition of drugs for treatment at this time can best reflect the inhibitory ability of drugs on the proliferation and growth of tumor cells. In order to avoid the interference factor of the influence of culture medium on tumor cells, a control group with only culture medium was used; neutral medium was used to minimize the effect of medium acidity on tumor cells.

Through the establishment of an OS mouse model, the effects of Sch B on OS in vivo were examined. The results demonstrated that Sch B effectively inhibited tumor growth and the occurrence of lung metastasis in OS.

Furthermore, drug-disease gene interactions of Sch B and OS were determined using network pharmacological analysis, followed by relevant signal pathway determination using GO functional annotation and KEGG pathway enrichment analysis. The key target changes in related signal pathways were then assessed, and it was demonstrated that Sch B primarily altered the key targets of the Wnt/ $\beta$-catenin and PI3K/Akt signaling pathways. In addition, in order to further confirm that the changes of the targets in the related signal pathways were involved in the effects of Sch B on OS cells, the cells were treated with the Wnt signaling pathway agonist, BML284, and the Akt phosphorylation activator, SC79, in combination with Sch B. Both BML284and SC79 partially reversed the inhibitory effects of Sch B on OS, this being the main novelty, to the best of our knowledge, of the present study.

In conclusion, the present study revealed that Sch B may be used in the treatment of OS in vitro and in vivo, and its potential anti-OS mechanism may be mediated through the inhibition of the Wnt/ $\beta$-catenin and PI3K/Akt signaling pathways. Therefore, it is suggested that Sch B may possibly serve as a novel drug target in the clinical treatment of OS. In future studies, the authors aim to further examine the effects of Sch B combined with cytotoxic drugs, as well as the internal mechanisms of these effects.

\section{Acknowledgements}

Not applicable.

\section{Funding}

The present study was supported by the National Natural Science Foundation of China (grant no. 81873998).

\section{Availability of data and materials}

The datasets used and/or analyzed during the current study are available from the corresponding author on reasonable request.

\section{Authors' contributions}

All authors (XL, JL, YW, JC, YH, SY, TT, NW, JZ, CY and MW) made substantial contributions to the study design. XL and JL critically revised the manuscript for important intellectual content. YW drafted the manuscript, and agreed to be accountable for the work in ensuring that questions related to the integrity of any part of the work are appropriately investigated and resolved. YW and XL confirm the authenticity of all the raw data. YW, CY, NW and JZ performed the experiments and acquired the data. NW, TT, SY, YH and JC analyzed and interpreted the data. All authors have read and approved the final manuscript.

\section{Ethics approval and consent to participate}

The present study was conducted according to the guidelines of the Declaration of Helsinki, and approved by the Ethics Committee of the First Affiliated Hospital of Chongqing Medical University (approval no. Research ethics 2020-503; date of approval, September 29, 2020).

\section{Patient consent for publication}

Not applicable.

\section{Competing interests}

The authors declare that they have no competing interests. 


\section{References}

1. Ottaviani G and Jaffe N: The epidemiology of osteosarcoma. Cancer Treat Res 152: 3-13, 2009.

2. Papakonstantinou E, Stamatopoulos A, Athanasiadis DI, Kenanidis E, Potoupnis M, Haidich AB and Tsiridis E: Limb-salvage surgery offers better five-year survival rate than amputation in patients with limb osteosarcoma treated with neoadjuvant chemotherapy. A systematic review and meta-analysis. J Bone Oncol 25: 100319, 2020.

3. Meazza C and Scanagatta P: Metastatic osteosarcoma: A challenging multidisciplinary treatment. Expert Rev Anticancer Ther 16: 543-556, 2016

4. Hattinger CM, Patrizio MP, Magagnoli F, Luppi S and Serra M: An update on emerging drugs in osteosarcoma: Towards tailored therapies? Expert Opin Emerg Drugs 24: 153-171, 2019.

5. Leong PK and Ko KM: Schisandrin B: A double-edged sword in nonalcoholic fatty liver disease. Oxid Med Cell Longev 2016 6171658, 2016

6. Nasser MI, Zhu S, Chen C, Zhao M, Huang H and Zhu P: A comprehensive review on Schisandrin $\mathrm{B}$ and its biological properties. Oxid Med Cell Longev 2020: 2172740, 2020.

7. Yang X, Wang S, Mu Y and Zheng Y: Schisandrin B inhibits cell proliferation and induces apoptosis in human cholangiocarcinoma cells. Oncol Rep 36: 1799-1806, 2016.

8. Nasser MI, Han T, Adlat S, Tian Y and Jiang N: Inhibitory effects of Schisandrin B on human prostate cancer cells. Oncol Rep 41: 677-685, 2019

9. Dai X, Yin C, Guo G, Zhang Y, Zhao C, Qian J, Wang O, Zhang X and Liang G: Schisandrin B exhibits potent anticancer activity in triple negative breast cancer by inhibiting STAT3. Toxicol Appl Pharmacol 358: 110-119, 2018.

10. Jiang Y, Zhang Q, Bao J, Du C, Wang J, Tong Q and Liu C: Schisandrin B suppresses glioma cell metastasis mediated by inhibition of mTOR/MMP-9 signal pathway. Biomed Pharmacother 74: 77-82, 2015.

11. Lv XJ, Zhao LJ, Hao YQ, Su ZZ, Li JY, Du YW and Zhang J: Schisandrin B inhibits the proliferation of human lung adenocarcinoma A549 cells by inducing cycle arrest and apoptosis. Int J Clin Exp Med 8: 6926-6936, 2015.

12. Pautke C, Schieker M, Tischer T, Kolk A, Neth P, Mutschler W and Milz S: Characterization of osteosarcoma cell lines MG-63, Saos-2 and U-2 OS in comparison to human osteoblasts. Anticancer Res 24: 3743-3748, 2004.

13. Jiao Y, Guo Y, Fan Y, Wang R, Li X, Wu H, Meng Z, Yang X Cui Y, Liu H, et al: Triggering of apoptosis in osteosarcoma 143B cell line by carbon quantum dots via the mitochondrial apoptotic signal pathway. Biomed Res Int 2020: 2846297, 2020.

14. Szklarczyk D, Gable AL, Lyon D, Junge A, Wyder S, Huerta-Cepas J, Simonovic M, Doncheva NT, Morris JH, Bork P, et al: STRING v11: Protein-protein association networks with increased coverage, supporting functional discovery in genome-wide experimental datasets. Nucleic Acids Res 47(D1): D607-D613, 2019.

15. Shannon P, Markiel A, Ozier O, Baliga NS, Wang JT, Ramage D, Amin N, Schwikowski B and Ideker T: Cytoscape: A software environment for integrated models of biomolecular interaction networks. Genome Res 13: 2498-2504, 2003.

16. Ashburner M, Ball CA, Blake JA, Botstein D, Butler $\mathrm{H}$, Cherry JM, Davis AP, Dolinski K, Dwight SS, Eppig JT, et al: Gene ontology: Tool for the unification of biology. Nat Genet 25 : 25-29, 2000

17. The Gene Ontology Consortium: The gene ontology resource: 20 years and still GOing strong. Nucleic Acids Res 47: D330-D338, 2019.

18. Kanehisa M: Post-genome Informatics. Oxford University Press, Oxford, 2000.

19. R Core Team: R: A language and environment for statistical computing. R Foundation for Statistical Computing, Vienna, Austria, 2012.

20. R Studio Team: R Studio: Integrated Development for R. R Studio, Inc., Boston, MA, 2015.

21. Stockhausen K: The Declaration of Helsinki: Revising ethical research guidelines for the 21st century. Med J Aust 172: 252-253, 2000

22. Lamouille S, Xu J and Derynck R: Molecular mechanisms of epithelial-mesenchymal transition. Nat Rev Mol Cell Biol 15: 178-196, 2014.
23. Rohani MG and Parks WC: Matrix remodeling by MMPs during wound repair. Matrix Biol 44-46: 113-121, 2015.

24. Clevers $\mathrm{H}$ and Nusse $\mathrm{R}$ : Wnt $/ \beta$-catenin signaling and disease. Cell 149: 1192-1205, 2012.

25. Xia P and Xu XY: PI3K/Akt/mTOR signaling pathway in cancer stem cells: From basic research to clinical application. Am J Cancer Res 5: 1602-1609, 2015.

26. Jafari M, Ghadami E, Dadkhah $\mathrm{T}$ and Akhavan-Niaki $\mathrm{H}$ PI3k/AKT signaling pathway: Erythropoiesis and beyond. J Cell Physiol 234: 2373-2385, 2019.

27. Fresno Vara JA, Casado E, de Castro J, Cejas P, Belda-Iniesta C and González-Barón M: PI3K/Akt signalling pathway and cancer. Cancer Treat Rev 30: 193-204, 2004.

28. Ritter J and Bielack SS: Osteosarcoma. Ann Oncol 21 (Suppl 7): vii320-vii325, 2010

29. Armstrong J and Dass CR: Doxorubicin action on mitochondria: Relevance to osteosarcoma therapy? Curr Drug Targets 19: 432-438, 2018

30. Harrison DJ, Geller DS, Gill JD, Lewis VO and Gorlick R: Current and future therapeutic approaches for osteosarcoma. Expert Rev Anticancer Ther 18: 39-50, 2018.

31. Hagleitner MM, Coenen MJ, Gelderblom H, Makkinje RR, Vos HI, de Bont ES, van der Graaf WT, Schreuder HW, Flucke U, van Leeuwen FN, et al: A first step toward personalized medicine in osteosarcoma: Pharmacogenetics as predictive marker of outcome after chemotherapy-based treatment. Clin Cancer Res 21: 3436-3441, 2015.

32. Qi F, Zhao L, Zhou A, Zhang B, Li A, Wang Z and Han J: The advantages of using traditional Chinese medicine as an adjunctive therapy in the whole course of cancer treatment instead of only terminal stage of cancer. Biosci Trends 9: 16-34, 2015.

33. Wang J, Fang Z, Song C, Kang H, Guo Q, Dong Y, Zhang Y, Peng R, Guan $\mathrm{H}$ and Li F: Schisandrin B inhibits osteoclastogenesis and protects against ovariectomy-induced bone loss. Front Pharmacol 11: 1175, 2020.

34. Gruber M, Handle F and Culig Z: The stem cell inhibitor salinomycin decreases colony formation potential and tumor-initiating population in docetaxel-sensitive and docetaxel-resistant prostate cancer cells. Prostate 80: 267-273, 2020.

35. Kume K and Nishizuka SS: Colony lysate arrays for proteomic profiling of drug-tolerant persisters of cancer cell. Anal Chem 89: 8626-8631, 2017

36. Mailand N, Gibbs-Seymour I and Bekker-Jensen S: Regulation of PCNA-protein interactions for genome stability. Nat Rev Mol Cell Biol 14: 269-282, 2013.

37. Wang SC: PCNA: A silent housekeeper or a potential therapeutic target? Trends Pharmacol Sci 35: 178-186, 2014.

38. Cui J, Dean D, Hornicek FJ, Chen Z and Duan Z: The role of extracelluar matrix in osteosarcoma progression and metastasis. J Exp Clin Cancer Res 39: 178, 2020.

39. Nieto MA, Huang RY, Jackson RA and Thiery JP: EMT: 2016. Cell 166: 21-45, 2016.

40. McCabe EM and Rasmussen TP: lncRNA involvement in cancer stem cell function and epithelial-mesenchymal transitions. Semin Cancer Biol 75: 38-48, 2021.

41. Skrzypek K and Majka M: Interplay among SNAIL transcription factor, MicroRNAs, long non-coding RNAs, and circular RNAs in the regulation of tumor growth and metastasis. Cancers (Basel) 12: 209, 2020.

42. Wang Y, Shi J, Chai K, Ying X and Zhou BP: The role of snail in EMT and tumorigenesis. Curr Cancer Drug Targets 13: 963-972, 2013.

43. Mendonsa AM, Na TY and Gumbiner BM: E-cadherin in contact inhibition and cancer. Oncogene 37: 4769-4780, 2018

44. Ramkumar N, Omelchenko T, Silva-Gagliardi NF, McGlade CJ, Wijnholds J and Anderson KV: Crumbs 2 promotes cell ingression during the epithelial-to-mesenchymal transition at gastrulation. Nat Cell Biol 18: 1281-1291, 2016.

45. Paolillo $\mathrm{M}$ and Schinelli S: Extracellular matrix alterations in metastatic processes. Int J Mol Sci 20: 4947, 2019.

46. Torzilli PA, Bourne JW, Cigler T and Vincent CT: A new paradigm for mechanobiological mechanisms in tumor metastasis. Semin Cancer Biol 22: 385-395, 2012.

47. Nørregaard KS, Jürgensen HJ, Gårdsvoll H, Engelholm LH, Behrendt $\mathrm{N}$ and Søe K: Osteosarcoma and metastasis associated bone degradation-A tale of osteoclast and malignant cell cooperativity. Int J Mol Sci 22: 6865, 2021.

48. Ogrodnik M, Salmonowicz H, Jurk D and Passos JF: Expansion and cell-cycle arrest: Common denominators of cellular senescence. Trends Biochem Sci 44: 996-1008, 2019. 
49. Goel S, DeCristo MJ, McAllister SS and Zhao JJ: CDK4/6 inhibition in cancer: Beyond cell cycle arrest. Trends Cell Biol 28: 911-925, 2018

50. Pack LR, Daigh LH and Meyer T: Putting the brakes on the cell cycle: Mechanisms of cellular growth arrest. Curr Opin Cell Biol 60: 106-113, 2019.

51. Montalto FI and De Amicis F: Cyclin D1 in cancer: A molecular connection for cell cycle control, adhesion and invasion in tumor and stroma. Cells 9: E2648, 2020.

52. Caruso JA, Duong MT, Carey JP, Hunt KK and Keyomarsi K: Low-molecular-weight cyclin E in human cancer: Cellular consequences and opportunities for targeted therapies. Cancer Res 78: 5481-5491, 2018.

53. D'Amelio M, Cavallucci V and Cecconi F: Neuronal caspase-3 signaling: Not only cell death. Cell Death Differ 17: 1104-1114, 2010.

54. Xu P, Cai X, Zhang W, Li Y, Qiu P, Lu D and He X: Flavonoids of Rosa roxburghii Tratt exhibit radioprotection and anti-apoptosis properties via the $\mathrm{Bcl}-2[\mathrm{Ca}(2+)] /$ Caspase-3/PARP-1 pathway. Apoptosis 21: 1125-43, 2016.

55. Cai Y, Cai T and Chen Y: Wnt pathway in osteosarcoma, from oncogenic to therapeutic. J Cell Biochem 115: 625-631, 2014.
56. Danieau G, Morice S, Rédini F, Verrecchia F and Royer BB: New insights about the Wnt $/ \beta$-Catenin signaling pathway in primary bone tumors and their microenvironment: A promising target to develop therapeutic strategies? Int J Mol Sci 20: 3751, 2019.

57. McQueen P, Ghaffar S, Guo Y, Rubin EM, Zi X and Hoang BH: The Wnt signaling pathway: Implications for therapy in osteosarcoma. Expert Rev Anticancer Ther 11: 1223-1232, 2011.

58. Revathidevi S and Munirajan AK: Akt in cancer: Mediator and more. Semin Cancer Biol 59: 80-91, 2011.

59. Yang Q, Jiang W and Hou P: Emerging role of PI3K/AKT in tumor-related epigenetic regulation. Semin Cancer Biol 59: 112-124, 2019.

60. Chen Y, Li H, Zhang W, Qi W, Lu C, Huang H, Yang Z, Liu B and Zhang L: Sesamin suppresses NSCLC cell proliferation and induces apoptosis via Akt/p53 pathway. Toxicol Appl Pharmacol 387: 114848, 2020.

61. Liang XX, Wang RY, Guo YZ, Cheng Z, Lv DY, Luo MH, He A, Luo SX and Xia Y: Phosphorylation of Akt at Thr308 regulates p-eNOS Ser1177 during physiological conditions. FEBS Open Bio 11: 1953-1964, 2021.

(i) This work is licensed under a Creative Commons Attribution-NonCommercial-NoDerivatives 4.0 International (CC BY-NC-ND 4.0) License. 